\title{
ALOFORMAÇÃO ANDRADINA: EXPRESSÃO DO ANTROPOCENO NO PLANALTO OCIDENTAL PAULISTA
}

Antonio Manoel dos Santos OLIVEIRA

José Pereira de QUEIROZ NETO

\begin{abstract}
RESUMO
O quadro geológico do Planalto Ocidental Paulista $\left(220.000 \mathrm{~km}^{2}\right)$ no estado de São Paulo é marcado pela ocorrência de depósitos sedimentares que colmatam os fundos de vale de primeira e segunda ordem, resultantes de uma excessiva produção de sedimentos, com abrangência regional, num curto intervalo de poucas dezenas de anos. Estes sedimentos têm como origem a manifestação de intensos processos erosivos consequentes à devastação das florestas primitivas, realizada pelo processo de colonização de origem europeia no século XX. Os depósitos podem ser reconhecidos no campo pela alternância nos sedimentos de camadas mais argilosas e mais arenosas, contendo artefatos que constituem indicadores inequívocos de sua origem antrópica. Podem ser detectados em imagens de satélite e em fotografias aéreas que permitem, de uma parte, verificar a extensão de suas ocorrências nos fundos dos vales e, de outra parte, a sua dinâmica ao longo do tempo. Assim, constata-se que ocorrem em toda a rede de drenagem do Planalto Ocidental Paulista, apesar de individualmente ocuparem extensões relativamente reduzidas em cada berço de drenagem. Por apresentarem expressão regional de ocorrência, características persistentes e por representarem um epiciclo geotecnogênico de grande importância, é cientificamente relevante que estes depósitos, que marcam a colonização do Planalto Ocidental Paulista, sejam reconhecidos como uma nova formação: a Aloformação Andradina, cujos critérios de definição seguiram o Léxico Estratigráfico do Brasil. A denominação Andradina, além de representar a localidade que teve o primeiro depósito a ser estudado (em 1994), constitui um dos principais locais de referência das pesquisas pioneiras realizadas por Pierre Monbeig, nos anos de 1940, e onde é possível reconhecê-la como um estratótipo, que não é resultante de um evento fortuito ou localizado, mas representa um quadro geológico configurado no Antropoceno, como vem sendo definida a nova época do Quaternário pela Comissão Estratigráfica da IUGS, marcada pela ação da humanidade como agente geológico.
\end{abstract}

Palavras-chave: Depósitos tecnogênicos; Epiciclo geotecnogênico; Colonização; Planalto Ocidental Paulista; Aloformação Andradina.

\section{ABSTRACT}

ANDRADINA ALLOFORMATION: THE ANTHROPOCENE EXPRESSION IN THE WESTERN PLATEAU OF STATE OF SÃO PAULO. The geological frame of the Western Plateau of the State of São Paulo (Planalto Ocidental Paulista), with an area of $220,000 \mathrm{~km}^{2}$, has sedimentary deposits on first-order valley bottoms resulting from recent and excessive regional sediment production over a few decades. These sediments were formed by intense erosion as a consequence of the devastation of the primitive forests due to European colonization in the $20^{\text {th }}$ century. The deposits can be identified in the field by alternating sandy and clayey layers with artifacts that indicate anthropic origin. They can be observed in satellite images and aerial photographs and, thus, their size on valley bottoms can be estimated and their dynamics can be analyzed over time. They occur in the entire drainage network of the Western Plateau, although 
individually their size is relatively small in each drainage. Because of their regional occurrence and persistent characteristics, and because they represent a very important geotechnogenic epicycle, these deposits, which mark the colonization of the Western Plateau, should be defined as a new formation, named "Andradina Alloformation", according to the Brazilian stratigraphic lexicon. The term "Andradina" refers to the city where the first deposit was studied in 1994, to one of the most important sites where Pierre Monbeig conducted pioneering research in the 1940's, and to the site where the Andradina stratigraphic unit was identified. This unit is not the result of a fortuitous or localized event, but represents a geological feature formed in the Anthropocene, which is a new geological epoch of the Quaternary defined by humanity as a geological agent and proposed by the International Union of Geological Sciences (IUGS).

Keywords: Technogenic deposits; Geotechnogenical epicycle; Colonization; Western Plateau of São Paulo; Andradina Alloformation.

\section{INTRODUÇÃO}

Sob a perspectiva do Antropoceno, o planeta Terra passa atualmente por processos geológicos, de dinâmica superficial, que apontam a humanidade como o mais novo e intenso agente geológico. Por isso o Antropoceno vem sendo avaliado como proposta para uma nova época do Quaternário pela Comissão Estratigráfica da IUGS (International Union of Geological Sciences) em seu Grupo de Trabalho sobre o Antropoceno da Subcomissão de Estratigrafia do Quaternário (SQS 2017).

Em decorrência da nova dinâmica superficial, os depósitos sedimentares em formação estão sendo marcados pelas condições antrópicas de origem, contendo indicadores que constituem testemunhos das ações do Homem.

Este artigo propõe a criação de uma nova unidade geológica estratigráfica no Planalto Ocidental Paulista, relativa ao Antropoceno na região, correspondente aos depósitos que se formaram nos fundos dos vales, testemunhos da ação antrópica da colonização desse planalto.

Neste sentido, o artigo, baseado nos fundamentos pertinentes aos conceitos de Antropoceno, depósitos tecnogênicos e aloformações, apresenta o meio ambiente e a colonização do Planalto Ocidental Paulista no século $\mathrm{XX}$, que imprimiu uma nova dinâmica geológica superficial, geotecnogênica, dando origem aos depósitos tecnogênicos dos fundos dos vales da região. O conjunto destes depósitos constitui a Aloformação Andradina proposta.

\section{CONSIDERAÇÕES FUNDAMENTAIS}

De maneira a fundamentar a proposta objeto deste artigo são em seguida elaboradas considera- ções a respeito do Antropoceno, dos depósitos tecnogênicos e das aloformações.

\subsection{Antropoceno}

Segundo a Subcomissão da Estratigrafia do Quaternário da International Union of Geological Sciences - IUGS (SQS 2017), o termo "Antropoceno" é um termo amplamente usado, desde que foi proposto por CRUTZEN \& STOERMER (2000) para definir o intervalo de tempo atual, no qual as condições ambientais e processos geológicos se apresentam significativamente alterados pelas atividades humanas.

Vários efeitos em que a ação humana parece ser decisiva vêm sendo monitorados, como as mudanças climáticas, os ciclos dos elementos como carbono, nitrogênio, fósforo e vários metais, a acidificação dos oceanos e as alterações significativas da biosfera com perdas de habitats e extinções de espécies. As atividades humanas têm provocado, de forma mais intensa, mudanças dos processos geológicos de dinâmica superficial, especialmente de erosão e transporte de sedimentos associados a uma variedade de processos antropogênicos, incluindo a colonização de territórios relativamente pouco alterados pela ocupação, expressa por assentamentos agrícolas e urbanos.

Os efeitos vêm sendo identificados em várias escalas, das locais às regionais e globais, com evidentes mudanças ambientais que vêm alterando as condições de sedimentação no planeta, tanto em termos quantitativos, expressos pelas taxas de produção de sedimentos das bacias hidrográficas, como pelas mudanças de composição dos sedimentos devido à presença de elementos 
produzidos artificialmente como plásticos e outros contaminantes (ZALASIEWSICZ et al. 2016).

O Grupo de Trabalho da SQS (2017) sobre o Antropoceno alerta que o termo ainda não é uma unidade geológica formalmente definida dentro da Escala de Tempo Geológico, porém sua formalização está sendo desenvolvida nesse grupo. Se o Antropoceno for aprovado dentro do Holoceno poderá ser uma idade geológica. Se for aprovado no mesmo nível hierárquico que as épocas Pleistoceno e Holoceno, sua aprovação implicará no fim do Holoceno.

Entretanto, em termos informais o Antropoceno vem sendo adotado pela comunidade científica para caracterizar as pesquisas nestas novas condições ambientais antropizadas, mesmo em áreas não geológicas como psicologia, sociologia (TOIVANEN et al. 2017) e em expressões culturais como o teatro (VORTICE DANCE COMPANY 2015).

Para o início do Antropoceno CRUTZEN \& STOERMER (2000) indicam o início da Revolução Industrial em 1800. TER-STEPANIAN (1988) propôs que o começo da transição para a nova época fosse considerado na última configuração quaternária da paisagem há cerca de 10.000 anos, enquanto seu final seria marcado, no futuro, pela completa configuração quinária ou tecnogênica, ou seja, quando todas as paisagens terrestres estiverem completamente alteradas pelo Homem, portanto não mais quaternárias (OLIVEIRA \& PELOGGIA 2014).

\subsection{Depósitos tecnogênicos}

WILKINSON (2005) comparou as taxas de denudação naturais, ao longo dos últimos 500 milhões de anos em todo o planeta, e as provocadas pelo Homem nos últimos milhares de anos e encontrou valores das taxas antropogênicas da ordem de 10 vezes maiores que as geológicas, quando essas taxas são comparadas entre si tendo como referencial comum a unidade de 1 milhão de anos, ou seja, no tempo geológico.

Esta erosão antrópica é a responsável pela formação de depósitos denominados depósitos tecnogênicos (CHEMEKOV 1983), importantes testemunhos da história do ser humano como agente geológico. À semelhança das formações geológicas que revelam a história do planeta, ou seja, os ambientes passados e seus agentes naturais, os depósitos tecnogênicos guardam os indicadores e testemunham os agentes antrópicos no ambiente marcado pelo processo civilizatório (OLIVEIRA et al. 2005).

Destacam-se nestas condições os depósitos induzidos (PELOGGIA et al. 2014) formados nos fundos dos vales a partir de eventos históricos que transformaram de forma radical o meio ambiente original. Estes são os casos dos processos de colonização de terras do Novo Mundo, reconhecidos na América do Norte como accelerated ou cultural valley deposits (HAPP et al. 2008) ou post-settlement alluvium (JOHNSON et al. 1980), termo também usado na Austrália (RUSTOMJI \& PIETSCH 2007). No Brasil, são mais frequentemente identificados como depósitos tecnogênicos dos fundos de vale (OLIVEIRA \& QUEIROZ NETO 1994, PELOGGIA et al. 2014).

Nos Estados Unidos, a identificação destes depósitos, cujos relatos mais antigos datam do começo do século passado (MOORE 1801 apud ROEHL et al. 1977, TAYLOR 1813 apud ROEHL et al. 1977), levou o Departamento da Agricultura (USDA) a realizar campanha de mapeamento das ocorrências no oeste americano (ROEHL et al. 1977), com o objetivo de estimar as taxas de produção de sedimentos com vistas à previsão de assoreamento de reservatórios que começavam então a ser planejados nos Estados Unidos. Com este mesmo objetivo foi realizada pesquisa no Brasil com base no estudo das ocorrências de depósitos tecnogênicos, formados no período da colonização do Planalto Ocidental Paulista (OLIVEIRA 1994).

ROEHL et al. (1977) elaboraram uma síntese a respeito dos depósitos americanos, destacando suas principais características: textura (em bacias de solos arenosos, os depósitos são mais grosseiros que o solo sotoposto); cores dos estratos (geralmente o solo enterrado, sotoposto, é mais escuro:

"a distinção pode ser feita entre uma areia branca ou clara sobre um solo muito escuro ou quase preto devido ao elevado conteúdo em matéria orgânica", que testemunha uma antiga superficie do terreno antes da colonização; compacidade (o depósito é menos denso e tem mais vazios); estratificação ("geralmente depósitos modernos mostram estratificações distintas, camadas lenticulares e estratificação cruzada"). Finalmente, os autores ponderam que "se é dificil reconhecer a espessura dos depósitos modernos através destas 
características; mourões de cerca, pontes, ferramentas e outros utensílios, tábuas de madeira e outros artefatos encontrados, parcial ou totalmente enterrados pelos depósitos, podem fornecer indicações úteis".

\subsection{Aloformações}

A estratigrafia do Antropoceno é ainda um tema importante de debate, pois está na origem da própria definição desta época (ZALASIEWICZ et al. 2011).

Segundo ETCHEBEHERE (2002) o Código Norte-Americano de Nomenclatura Estratigráfica define uma unidade aloestratigráfica como sendo um corpo estratiforme mapeável de rochas sedimentares, identificado e definido com base nas descontinuidades que o limitam. Ainda segundo o autor este novo enfoque estratigráfico é aplicável onde as classificações litoestratigráficas tradicionais se revelam impróprias, em especial no caso dos depósitos quaternários de natureza continental, como os terraços fluviais. Estes corpos apresentam-se, muitas vezes, com pequenas espessuras, formando conjuntos de ocorrências com ampla distribuição em área, mas com unidades de pequena extensão individual.

PELOGGIA (2003) discute o problema estratigráfico dos depósitos tecnogênicos, considerando as aloformações definidas por diversos autores. A Aloformação Carrapato foi definida na região do Bananal por MOURA \& MELLO (1991) e referida por RIBEIRO et al. (1996) como depósito tecnogênico de encosta. A Aloformação Ribeirão Mombaça foi definida por MELLO (1997) como depósito de baixo terraço e planícies de inundação de cursos d'água do médio vale do Rio Doce, com evidências de ações antrópicas suficientes para o autor denominálos depósitos tecnogênicos. PELOGGIA (1998) propôs a Formação Várzea do Carmo para designar o conjunto de depósitos tecnogênicos formados nas planícies fluviais da cidade de São Paulo, deixando em aberto a classificação formal em aloestratigrafia ou outra.

Se todos os depósitos formados direta ou indiretamente pelo homem são tecnogênicos, nem todos podem ser considerados suficientemente expressivos para configurar o domínio de uma aloformação. AB' SABER (1969a) esclarece que qualquer ocorrência isolada de depósitos modernos é apenas uma estação geológica de significação paleogeográfica regional restrita e incompleta.
E prossegue o autor: "entretanto, qualquer ocorrência antevista do ponto de vista fisioestratigráfico e se possível cartográfico, passará a ter um significado geomorfológico mais científico e digno de crédito".

Em outras palavras, se um conjunto de depósitos tecnogênicos pode ser submetido a um raciocínio indutivo que traduza as ocorrências em uma lei geral, sintética, que expressa seu significado regional, então pode-se avançar para a denominação de uma aloformação. Caso contrário uma ocorrência isolada, embora significativa do ponto de vista tecnogênico, não participa de um conjunto que represente uma aloformação.

Por isso, a aplicação do conceito de Aloformação ganha seu pleno significado quando os depósitos tecnogênicos expressam regionalmente um efeito de um evento ou intervenção humana histórica definida, em uma região determinada, o que é o caso dos depósitos tecnogênicos dos fundos de vale do Planalto Ocidental Paulista.

\section{QUADRO GEOLÓGICO DO PLANALTO OCIDENTAL PAULISTA}

O Planalto Ocidental Paulista ocupa uma área de aproximadamente $126 \mathrm{mil} \mathrm{km}^{2}$, desde cerca de $200 \mathrm{~km}$ a oeste da capital do estado (São Paulo) até o rio Paraná, na fronteira com o estado do Mato Grosso do Sul. Constitui o mais extenso compartimento de relevo do estado de São Paulo, ocupando cerca de metade de sua área, entre as latitudes de $20^{\circ}$ e $23^{\circ} \mathrm{S}$ e as longitudes de $48^{\circ}$ e $53^{\circ} \mathrm{W}$.

O Planalto é limitado pelos rios Paraná, Grande e Paranapanema, respectivamente, a oeste, norte e sul, correspondentes às fronteiras do estado de São Paulo com os estados do Mato Grosso do Sul, Minas Gerais e Paraná. A leste, o limite foi estabelecido, segundo o mapa geomorfológico elaborado pelo IPT (PONÇANO et al. 1981), com base em ALMEIDA (1964), no contato com a província geomorfológica das Cuestas Basálticas (Figura 1A).

Esteplanalto foi esculpido emrelevolevemente ondulado com predomínio de colinas amplas (ROSS \& MOROZ 1997), predominantemente em arenitos do Grupo Bauru (Figura 1B), cretácicos e, secundariamente, em basaltos da Formação Serra Geral, subjacente aos arenitos, ocorrendo nos fundos de alguns vales (PONÇANO et al. 1981). Formações mais recentes correspondem a depósitos aluvionares que ocorrem nos leitos dos rios de 

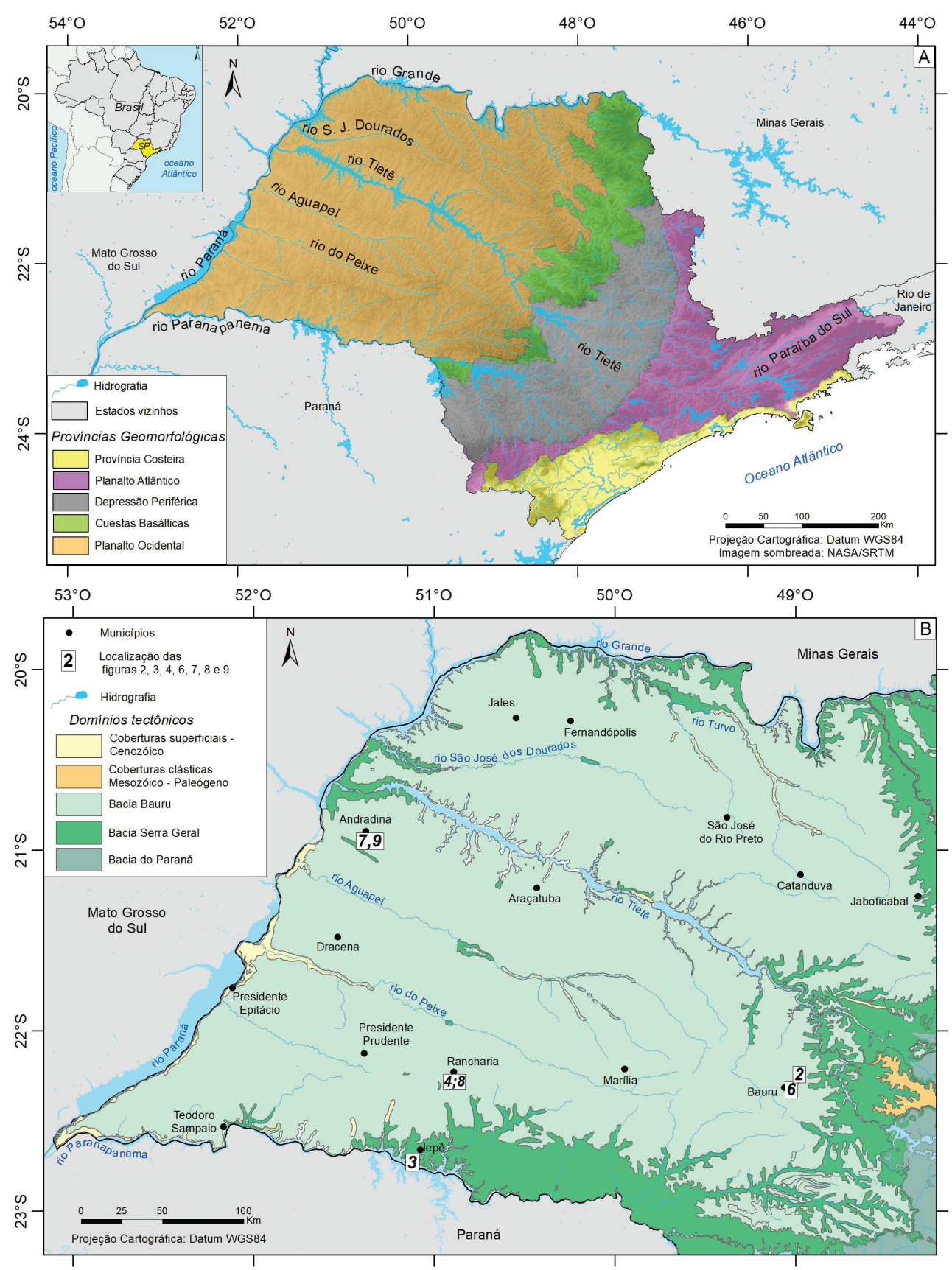

FIGURA 1 - (A) O Planalto Ocidental Paulista no Estado de São Paulo. Províncias geomorfológicas, de acordo com PONÇANO et al. (1981): I - Província Costeira, II - Planalto Atlântico, III - Depressão Periférica, IV Cuestas Basálticas, V - Planalto Ocidental. (B) Domínios tectônicos da porção oeste do estado de São Paulo (PERROTTA et al. 2005).

maior porte da região, destacando-se o Tietê, Peixe, Aguapeí, São José dos Dourados e Turvo. Alguns autores consideram também os coluviões como depósitos recentes (SALLUN et al. 2007), enquanto pesquisas de outros autores apontam coluviões como diferenciações pedológicas de horizontes pedológicos e não camadas (CASTRO 1989).
Segundo ALMEIDA et al. (1981), o Grupo Bauru foi depositado em área deprimida relativamente aos soerguimentos marginais e à zona central da Bacia Sedimentar do Paraná durante o Cretáceo Superior, recobrindo as lavas basálticas da Formação Serra Geral. Suas principais formações - Marília, Adamantina, Santo 
Anastácio e Caiuá - são de natureza predominantemente arenítica.

Não tendo sido reconhecidas formações terciárias no Planalto, ALMEIDA et al. (1981) supõem que o soerguimento epirogênico foi o movimento predominante, prevalecendo processos morfogenéticos erosivos. Segundo os referidos autores, sendo o território drenado por ampla rede fluvial e faltando geralmente condições tectônicas de fixação de sedimentos durante o Cenozoico, a sedimentação limitou-se, em todo o estado de São Paulo, às bacias tafrogênicas e aos depósitos de reduzidas áreas.

SALLUN \& SUGUIO (2006) também destacam a ausência de depósitos terciários no Planalto, sugerindo que neste período, prevaleceram processos essencialmente erosivos na região em contínuo soerguimento. De fato, PONÇANO et al. (1981) identificaram as coberturas cenozoicas do Planalto Ocidental Paulista constituídas essencialmente por depósitos aluvionares, elúvios e colúvios quaternários com distribuição restrita e governada pelos grandes cursos d'água.

Vários autores destacaram a presença de depósitos cenozoicos no Planalto com denominações diversas como terraços (AB' SABER 1969b, GUIDICINI \& SILVA 1972), depósitos superficiais cenozoicos (LEPSCH 1977) ou formações superficiais (QUEIROZ NETO \& JOURNAUX 1978).

MELO \& PONÇANO (1983) propuseram nova sistematização do conhecimento sobre a gênese, distribuição e estratigrafia dos depósitos cenozóicos no estado de São Paulo, fazendo ampla revisão da literatura. MORAES REGO (1933) foi pioneiro na identificação de tais depósitos como terraços ao longo das margens dos rios Paraná e Paranapanema, também relatados por AB' SABER (1969b).

Vários autores classificaram como depósitos cenozoicos originados pelo retrabalhamento do arenito Bauru e destacaram como indicadores as linhas de pedra, que às vezes contêm fragmentos de crosta limonítica na base de solos ou coluviões, com interpretações genéticas que apontam para fases de pediplanização, que ora estão sendo retrabalhadas no clima atual mais úmido (PENTEADO et al. 1973, QUEIROZ NETO et al. 1977, MELO \& PONÇANO 1983). Outras observações de ocorrências são relatadas na literatura, porém sempre de ocorrência restrita e descontínua ao longo dos eixos dos grandes cursos d'água como os terraços no Vale do Rio do Peixe mapeados por ETCHEBEHERE et al. (1999), com evidências de neotectônica. Podem também ser citadas pesquisas sobre depósitos arenosos neocenozoicos que capeiam arenitos da Formação Pirambóia na transição do Planalto Ocidental para a Depressão Periférica Paulista na região de São Pedro (MELLO et al. 2001, PINHEIRO 2014, PINHEIRO \& QUEIROZ NETO 2016).

Pesquisa realizada por SALLUN et al. (2007) concluiu pela proposição do Alogrupo Alto Rio Paraná, englobando os depósitos cenozoicos identificados pelos autores supracitados relativos a depósitos coluvionares (Aloformação Paranavaí) e aluviais (Aloformação Paraná). Segundo os autores, a Aloformação Paranavaí é composta por depósitos coluviais homogêneos, arenáceos e rudáceos, originados in situ ou com transporte restrito, a partir de unidades litoestratigráficas cretáceas intemperizadas, principalmente da Supersequência Bauru. A Aloformação Paraná é formada por terraços de origem fluvial, associados à paleodrenagem do Alto Rio Paraná, embutidos na Aloformação Paranavaí. Ainda segundo os autores, os registros da sedimentação do Alto Rio Paraná, há no mínimo $1 \mathrm{Ma}$ até os dias atuais, testemunhariam importantes mudanças paleoclimáticas e/ou eventos neotectônicos, que permitem sistematizar as fases evolutivas geológico-geomorfológicas cenozoicas da área de estudo.

Estes estudos acima referidos, não fazem menção à presença de formações de origem antrópica. De maneira geral, no Brasil, ainda são poucos os trabalhos que identificam depósitos com essa possível origem, sob a perspectiva geológica.

\section{O MEIO AMBIENTE DO PLANALTO PRÉ-COLONIZAÇÃO}

Como todo meio ambiente, o Planalto Ocidental Paulista deve ser considerado como um meio em transformação. Nas antigas condições geobiológicas naturais, primitivas, o Planalto evoluiu durante o Quaternário, conforme os indicadores apontados no item anterior, ou seja, depósitos cenozoicos e aloformações Paraná e Paranavaí, de acordo com a proposta de SALLUN et al. (2007). A partir da colonização europeia - últimos 150 anos de transformação - a fase mais drástica foi a primeira, a do desmatamento a ferro e fogo (DEAN 2004), que em poucas dezenas de anos eliminou drasticamente a vegetação primitiva e introduziu manejos do solo incomparáveis com quaisquer processos naturais. 
MONTEIRO (1976) considera que, embora o Planalto se encontre no limite de duas zonas climáticas, a intertropical e a subtropical, persiste, nas duas, um período seco característico, no cômputo dos índices médios de precipitação.

Estes índices, médios anuais, no Planalto, variam, segundo MONTEIRO (1973), entre $1.100 \mathrm{e}$ $1.400 \mathrm{~mm}$. MONTEIRO (1976) destaca o Planalto Ocidental como "a vasta área paulista em que se define um periodo seco (indices pluviais mensais inferiores a $60 \mathrm{~mm}$ de abril a setembro"). Pela classificação de Köppen, o clima é Cwa, ou seja, quente com inverno seco, com precipitações médias anuais da ordem de $1.000 \mathrm{~mm}$. A precipitação máxima diária para períodos de retorno de 10 e 50 anos foi estimada em 106,5 e 135,1 mm, respectivamente (VIEIRA et al. 1991).

Sob estas condições climáticas e com uma cobertura vegetal da Mata Atlântica desenvolveram-se os processos morfopedológicos, moldando as colinas e os solos arenosos a partir do substrato arenítico, Latossolos, Argissolos (podzólicos) e Neossolos Quartzarênicos (areia quartzosas).

A cobertura vegetal é a Mata Atlântica, constituída, na maior parte, por floresta mesofítica semi-decídua (SALIS et al. 1995, TORRES et al. 1997, BRANNSTROM 2002). Ocorrem também cerrado e cerradão em áreas mais restritas (VICTOR 1974, LEITÃO FILHO 1992).

No mapa organizado por ALONSO (1977), a vegetação primitiva do Planalto correspondia, na sua maior parte, a uma floresta subcaducifólia tropical e, secundariamente, a áreas restritas de cerrado. $\mathrm{O}$ autor considera a floresta como intermediária entre formações florestais perenes e as não florestais, representando o clima úmido com estação seca bem marcada, que caracteriza a região (MONTEIRO 1976).

VICTOR (1974) distingue duas florestas: a floresta latifoliada tropical, que domina o Planalto "envolvendo as bacias hidrográficas entre o rio Grande, ao norte, e o rio Paranapanema, a sudoeste", e a floresta latifoliada tropical semidecídua, que ocorre em algumas áreas das bacias do rio do Peixe, Aguapeí, Médio Tietê e São José dos Dourados.

Ainda segundo o autor, a primeira é mais exuberante com espécimes vegetais com alturas superiores a $30 \mathrm{~m}$. A segunda, mais pobre, "provavelmente devido à interação dos fatores clima e solo", com espécimes vegetais não tão altos, até 20 ou $25 \mathrm{~m}$. Entretanto, o autor assinala que as espécies das duas formações são fundamentalmente as mesmas e conhecidas popularmente por "peroba, pau d'alho, figueira, jequitibá, pau-marfim, jatobá, jacarandá paulista, caviuna, cabreúva, açoita-cavalo, ipê, braúna e vinhático".

MONBEIG (1984), que testemunhou a ocupação do Planalto no início do século XX, também assinala a interação do clima e do solo como os principais fatores que determinaram a cobertura vegetal primitiva. O autor destaca a "floresta da terra roxa" e, apoiando-se em RAWITSCHER (1944), descreve-a com quatro horizontes ou andares vegetais: um horizonte de árvores dominantes, com $30 \mathrm{~m}$ ou mais, um segundo andar de árvores, um terceiro andar de samambaias e palmeiras de 5 a $15 \mathrm{~m}$ e, finalmente, um horizonte herbáceo. Nos solos de arenito, o autor descreve um conjunto de menor porte, destacando os seguintes horizontes: um andar superior, que não ultrapassa $20 \mathrm{~m}$, um andar que pode atingir $15 \mathrm{~m}$ e um horizonte inferior de arbustos.

Quanto ao cerrado, ALONSO (1977) alerta para o fato deste não constituir uma fisionomia única, ocorrendo gradações desde florestas (cerradão) às formações herbáceo-arbustivas (cerrados ralos). MONBEIG (1984) destaca a associação dos cerrados aos solos arenosos, "sem elementos calcários". VICTOR (1974) descreve o cerradão em 3 andares: árvores de 10 a $18 \mathrm{~m}$ de altura, onde destaca o faveiro, o angico, a candeia, a copaíba, o pau-jacaré, o jacarandá- do-campo, a mangabeira, a imburana; um segundo andar, constituindo um sub-bosque, com arbustos e pequenas formas arbóreas, não ultrapassando a altura de 5 a $6 \mathrm{~m}$, e, finalmente, um andar inferior de espécies umbrófilas, rasteiras ou de pequeno porte.

Embora todos os autores identifiquem variações marcadas pela distribuição dos solos e sensíveis às nuances climáticas e à ocorrência dos solos, todos eles convergem para a configuração, em quase todo o Planalto, de uma densa cobertura vegetal. Este aspecto é relevante, pois, sendo significativa, a cobertura vegetal, resultante da interação natural com o clima, o relevo e os solos, encontrava-se em equilíbrio com tais componentes do meio ambiente. Este equilíbrio, dinâmico, estava condicionado por um balanço hídrico, cujos elementos de escoamento superficial, infiltração, percolação subterrânea e cursos d'água foram ajustados durante milhares de anos de flutuações climáticas do Quaternário, com moderada manifestação tectônica (ETCHEBEHERE et al. 2005).

No tocante à ocupação, segundo WAIBEL (1955), esta região do oeste paulista, ainda no pri- 
meiro decênio do século XX, era desconhecida e povoada apenas por um pequeno grupo de índios e intrusos, na acepção do autor, como aventureiros que penetram não oficialmente na região.

Importante considerar que a ocupação indígena do planalto também provocou alterações na cobertura vegetal, devido a prática de agricultura itinerante. Os terrenos submetidos a este manejo indígena podem ter se recuperado espontaneamente ao longo dos anos na forma de cerradinhos ou quiçaças, formações vegetais secundárias, sobretudo quando ocorrem próximos a cursos d'água, sítios preferidos pelos índios para instalar suas aldeias, como aventa MONBEIG (1984). De fato, LEITE (1970) constata que as áreas onde as matas foram derrubadas, quando abandonadas, apresentam crescimento de uma vegetação pobre, sem correspondência com a original, sobretudo às margens dos cursos d'água, que, quando intocadas, apresentam naturalmente matas mais exuberantes e não quiçaças.

Entretanto, as ações indígenas permaneceram pontuais e, de uma maneira geral, todos os autores convergem para a configuração da paisagem "primitiva" de que havia em quase todo o Planalto uma densa cobertura vegetal, sendo a sua constituição associada aos solos e nuances climáticas. Estas características começaram a ser extensamente alteradas com a chegada do colonizador europeu.

\section{A COLONIZAÇÃO DO PLANALTO}

As primeiras incursões do europeu, como a dos bandeirantes, já prenunciavam a devastação, testemunhada por Florence na década de 1820: "quando a gente por desenfado atira fogo aos campos... mesmo sem qualquer motivo forte" (FLORENCE 1977).

MONBEIG (1984) assinala que as condições naturais teriam ficado "adormecidas" ou latentes, como estiveram durante longos séculos de ocupação indígena, se o movimento colonizador não as tivesse "despertado", fazendo manifestar os fatores limitantes à ocupação extensiva, até então não mobilizadas, por exemplo, a erodibilidade dos solos. Estes limites, "rompidos" pela colonização, provocaram a manifestação dos fatores condicionantes que comandaram as transformações rumo a novo meio ambiente, antropizado, não natural. Pode-se considerar que esta transformação geotecnogênica consistiu numa espécie de humanização da natureza. É este o quadro em que o Planalto foi então extensamente colonizado e a história recente começou assim a ser escrita.

A partir da colonização, às condições naturais foram acrescidas as condições antrópicas, que se manifestaram, de forma mais intensa, há cerca de 150 anos, iniciadas por extenso desmatamento, a ferro e fogo (DEAN 2004) que, em poucas dezenas de anos, eliminou drasticamente a vegetação primitiva e introduziu manejos do solo incomparáveis com quaisquer processos naturais anteriores.

Segundo OLIVEIRA \& BRANNSTROM (2004), um encadeamento de fatores concorreu para a rápida colonização do interior do estado de São Paulo, desde terras estrangeiras até o mais distante rincão do oeste paulista: a expansão do consumo e a crescente importação do café pela Europa e pela América do Norte; o aumento dos capitais dos fazendeiros brasileiros que financiaram a construção de ferrovias; as imigrações de europeus e asiáticos para trabalhar nas lavouras, assim como de nordestinos; etc.

Como disse MONBEIG (1984): "Desde o seu início, a marcha para oeste foi um episódio da expansão da civilização capitalista, nas duas margens do Atlântico. Ambas não cessaram de ser solidárias". Mas se o grande impulso inicial foi dado pelo café (PICCHIA 1927), também devem ser considerados nessa colonização o algodão e a pecuária. Os plantadores de algodão, como os de café, também recebiam importantes subsídios do governo pelo desenvolvimento de novas variedades e oferta de mão de obra, como de imigrantes nordestinos (BRANNSTROM 1998).

Embora a história do uso do solo não tenha sido a mesma em todo o Planalto Ocidental, com áreas de usos predominantes diferenciados, de grandes pastagens, culturas de café e algodão, o desmatamento foi comum a todas elas. Na década de 1930, o assim chamado sertão paulista, como grande espaço contínuo, já se restringia a uma faixa de 100 a $200 \mathrm{~km}$ ao longo do rio Paraná (MONBEIG 1984). Este autor acompanhou a marcha pioneira do povoamento do interior paulista de 1937 a 1949, documentando-a em sua tese de doutorado à Sorbonne (Paris, França), defendida em 1950, destacando-se como uma das mais importantes testemunhas da transformação do interior paulista.

Segundo OLIVEIRA \& BRANNSTROM (2004) o uso extensivo do solo iniciou sua marcha decisiva no Planalto Ocidental entre 1880 e 1910, comandada pelos cafeicultores, como 
prosseguimento do processo de ocupação de terras pelo café que, principiando no estado do Rio de Janeiro, avançou pelo vale do Paraíba no estado paulista, se dirigindo para o extremo oeste do estado de São Paulo.

As queimadas foram iniciadas já no século XIX (FLORENCE 1977) em expedições ao interior e se sucederam extensas e persistentes ao longo dos primeiros anos do século XX para dar lugar ao café, algodão, amendoim e pastagens, eliminando de forma radical as coberturas vegetais. Nos anos de 1960 a vasta região do Planalto Ocidental Paulista já se encontrava quase totalmente desnudada.

A esta primeira alteração ambiental promovida pela colonização, sucederam-se outras alterações dentre as quais podem ser destacadas aquelas provocadas pelo processo de urbanização desde os anos de 1960; pela substituição das culturas agrícolas por outras e pela pecuária; pela construção de barragens de grande porte no rio Tietê e nos principais rios que delimitam o Planalto - o Grande, o Paraná e o Paranapanema - que transformaram seus principais cursos d'água em lagos artificiais, durante os anos de 1960 a 1990 (DEAN 2004).

Entretanto, deve-se reconhecer a superioridade da intensidade da primeira intervenção sobre as seguintes, pelo simples fato de que, em poucos anos, foi praticamente suprimido o componente biótico natural do meio ambiente e introduzido o componente civilizatório trazido pelos colonizadores.

Em cerca de 50 anos a região praticamente perdeu um dos componentes primitivos do meio ambiente natural: o meio biótico, alterando profundamente o balanço hídrico. Depois de milhares de anos de uma dinâmica natural dos processos geológicos superficiais, a eliminação de um dos principais fatores condicionantes dessa dinâmica, alterou de forma radical o balanço hídrico e o comportamento das águas de escoamento e infiltração nos terrenos agora desnudos.

Esse desequilíbrio hídrico passou a promover as alterações das coberturas pedológicas que em geral se apresentam muito sensíveis ao comportamento das águas, por sua natureza arenosa nas ocorrências das formações do Grupo Bauru. Solos altamente erodíveis passaram a sofrer entalhes erosivos, sulcos e ravinas, e a manifestar erosão interna na forma de voçorocas nas cabeceiras das nascentes dos cursos d'água, cujos sedimentos colmataram os fundos de vale de primeira e se- gunda ordem formando os depósitos tecnogênicos (OLIVEIRA \& QUEIROZ NETO 1994).

\section{A DINÂMICA GEOTECNOGÊNICA}

A velocidade da eliminação do componente biótico do sistema primitivo - rocha-clima-solovegetação-fauna - ocorreu, na perspectiva do tempo geológico, como um instante, ou seja, com o significado de uma catástrofe geológica.

A perda da cobertura florestal foi seguida por plantações de café e de algodão e, também, pastagens em grandes propriedades, culturas de subsistência nas pequenas propriedades, primeiros núcleos urbanos e redes de estradas vicinais, além das estradas de ferro e de rodagem. Estas formas de usos do solo provocaram profunda alteração dos ecossistemas e dos processos geobiodinâmicos presentes na primitiva interação dos componentes do meio ambiente.

O novo quadro que se estabelece com a denudação é geologicamente inusitado pois, até esse momento da história do planeta, os ciclos de dinâmica geológica seguiam um modelo cíclico, como proposto por ERHART (1956), de sucessão de fases de biostasia e de resistasia. $\mathrm{Na}$ fase de biostasia prevaleceria a pedogênese que se manifesta em climas úmidos e predomínio de intemperismo químico na formação de solos espessos, condicionando coberturas vegetais exuberantes, ao menos desde o Período Carbonífero, acompanhadas do desenvolvimento da fauna. Já na fase de resistasia prevaleceria a morfogênese que se manifesta em climas secos ou semiáridos, com intemperismo predominantemente físico e manifestação de processos erosivos intensos em solos pedregosos ou afloramentos rochosos que não possibilitam o desenvolvimento de uma vegetação exuberante. Estas condições podem ser constatadas hoje nas áreas não afetadas de forma significativa pelo Homem, na Amazônia biostásica e no Saara resistásico.

No novo momento ambiental instaurado, o Planalto desnudado, sem que tenha havido alteração do clima, favorável à biostasia, passa por uma transformação à condição resistásica. Embora esta nova condição possa ser favorável às culturas agrícolas e aos rebanhos domesticados, ela manifesta processos erosivos intensos.

Estes processos erosivos não pertencem mais à dinâmica geológica, mas a uma nova dinâmica, que pode ser denominada geotecnogênica, pois só se manifestaram devido à ação antrópica. Esta 
condição foi por isto denominada por AB'SABER (1968) resistasia antrópica.

No fator condicionante clima, a irregularidade das precipitações aponta para a manifestação da erosão (SANTANA 1991), especialmente ao desenvolvimento de feições erosivas lineares (VIEIRA 1978), reconhecidas como as de maior potencial de liberação de sedimentos (WALLING 1983).

Além disso, chuvas de elevada intensidade, acima de $25 \mathrm{~mm} /$ hora (OLIVEIRA 1994), são capazes de deflagrar erosões de forma catastrófica, com mobilização imediata de muitas toneladas de sedimentos, como assinalado por PELLERIN et al. (1975) na região de Marília em outubro de 1972, quando estas chegaram a atingir $300 \mathrm{~mm}$ em 4 dias, promovendo a evolução das cabeceiras das voçorocas da região e fenômenos de liquefação de areias gerando ravinas. Estes autores relatam também a evolução de ravinas com chuvas acumuladas de $40 \mathrm{~mm}$ em três horas e meia na mesma região.

No fator solos, a elevada erodibilidade dos solos oriundos do arenito, sejam os Latossolos Vermelhos de textura arenosa e os Argissolos Vermelho-Amarelos de textura arenosa/média em relevos suaves - ondulados a ondulados, favoreceram os sulcos, as ravinas e as voçorocas. Nas áreas de ocorrência de basaltos, seus Latossolos Vermelhos de textura argilosa (latossolos roxos) e Nitossolos Vermelhos (terras-roxas estruturadas) apresentam maior resistência à erosão, mas são restritas aos fundos dos vales.

KERTZMAN et al. (1995) destacam os solos mais comuns do Planalto Ocidental e que mais favoreceram a erosão: os espessos Latossolos arenosos dos topos das colinas, que podem sofrer ravinamentos profundos por escoamento concentrado e os Argissolos das vertentes que são abrúpticos de textura arenosa/média, altamente suscetíveis à erosão.

Estas manifestações erosivas correspondem, portanto, às respostas do desequilíbrio do balanço hídrico que era comandado pelas coberturas vegetais (PRANDINI et al. 1976, 1982) com seus papéis de interceptação das chuvas, retardamento do escoamento superficial, promoção da evaporação na água retida na sua superfície foliar e nos caules, após as chuvas, e a transpiração. Portanto, a eliminação da cobertura vegetal provocou a perda de proteção do solo do impacto direto da chuva, a liberação e concentração do escoamento superficial, a redução da evaporação imediata após as chuvas e a eliminação da transpiração da floresta.

Tais alterações tiveram profundo impacto no comportamento da água, configurando um forte desequilíbrio hídrico. O escoamento superficial passou a se manifestar na forma de enxurradas que, inicialmente, descobriram os solos, carreando a serrapilheira encostas abaixo e, em seguida, desprenderam as partículas de solo, gerando erosões cuja linearidade representa a origem antrópica, na forma de sulcos e ravinas.

As infiltrações iniciais no solo, mais favorecidas pela perda da cobertura vegetal, promoveram a ascensão do freático que foi testemunhado pelos colonizadores pioneiros, conforme os registros de MONBEIG (1984) e de OLIVEIRA (1994), seja pelo aparecimento de surgências de água em posições mais elevadas nas vertentes e nos talvegues das cabeceiras de drenagem, seja nos poços ou cisternas escavados pelos colonizadores que se encheram de água após o desmatamento.

Esta ascensão do freático atingiu os horizontes pedológicos acima da zona hidromórfica, resultando na desestruturação dos solos, especialmente os colapsíveis, frequentes no Planalto Paulista (VARGAS 1973), que ao perderem sua estrutura provocam o colapso e afundamento do terreno, concentrando o escoamento superficial e favorecendo o sulcamento e ravinamento.

Nas zonas de concentração do escoamento subterrâneo, nas cabeceiras de drenagem, onde o freático aflora em surgências d'água formando os pequenos cursos d'água, a ascensão do nível provoca um aumento dos gradientes de percolação que, ao ultrapassar certos limites, tem capacidade de erodir os solos arenosos finos de baixa coesão, promovendo o piping - erosão subterrânea, tubular e regressiva. Este fenômeno leva ao abatimento do terreno provocando a sinergia da concentração dos escoamentos, superficiais e subterrâneos, e o desenvolvimento das voçorocas de cabeceiras de drenagem, o que resulta no recuo erosivo das mesmas (RODRIGUES 1982) (Figura 2).

Milhares de voçorocas e ravinas eclodiram assim na região como processo de busca de reajuste dos solos e vertentes às novas condições, em direção a um novo equilíbrio do balanço hídrico, durante a transição do ambiente natural para o antropizado.

A perda de solos na região foi intensa e produziu uma carga instantânea de sedimentos que colmataram os cursos d'água formando depósitos 

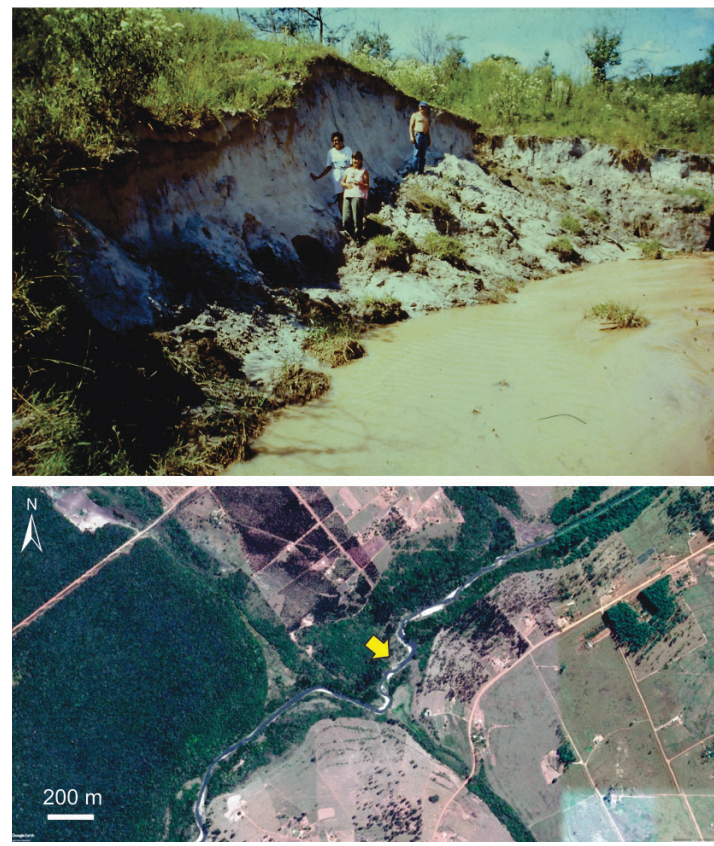

FIGURA 2 - Entalhe do canal com erosão fluvial. Cavidades no talude formadas por piping provocaram o afundamento do terreno, onde se concentrou o escoamento trazendo e depositando sedimentos (cabeceiras do rio Bauru, 1989). Abaixo, imagem de satélite Digital Globe (Fonte: Google Earth) da área (Rio Bauru, Bacia do Rio Tietê, Município de Bauru).

colúvio-aluvionares, de caráter denominado tecnogênico, uma vez que não existiriam sem a ação do ser humano.

Ao longo dos anos seguintes, durante o século XX, verifica-se que os processos erosivos no Planalto Ocidental Paulista, especialmente as voçorocas, foram perdendo intensidade e atingindo aos poucos certa estabilidade, de tal forma que as idades das voçorocas dessa região correspondem ao tempo de ocupação dos terrenos (IWASA \& PRANDINI 1980, PONÇANO \& PRANDINI 1987). A redução do aporte de sedimentos favoreceu o entalhe dos depósitos tecnogênicos formados nos fundos dos vales (OLIVEIRA 1990, OLIVEIRA \& QUEIROZ NETO 1994).

A relação existente entre a dinâmica fluvial e a produção de sedimentos nas bacias hidrográficas é descrita por LEOPOLD et al. (1964): "um aumento da produção de sedimentos na bacia produz agradação no canal fluvial e uma diminuição da produção de sedimentos produz degradação". Os autores apresentam, como exemplo, os efeitos que se produzem num rio, a jusante do local onde é implantada uma barragem: "a combinação de água limpa e do regime de escoamento leva à erosão do canal".

\section{OS DEPÓSITOS TECNOGÊNICOS DOS FUNDOS DE VALE}

Embora no Brasil ainda sejam poucos os trabalhos que identificam depósitos com possível origem antrópica, já foram citados cones de dejeção ligados a voçorocas na legenda de Ações Antrópicas da Carta Geomorfológica do Vale do Rio do Peixe, em Marília, SP (QUEIROZ NETO \& JOURNAUX 1978). RICH (1953) destaca como um dos problemas geológicos e geomorfológicos brasileiros a origem de sedimentos fluviais na região de Iguape, aventando a possibilidade de terem sido formados devido ao desmatamento. BITTENCOURT (1978) chega mesmo a propor um modelo de deposição de sedimentos e entalhe do ribeirão dos Ratos, PR, fundamentado na história do uso do solo da região.

No Planalto Ocidental Paulista, é provável que alguns mapeamentos tenham considerado a presença de depósitos tecnogênicos com outras denominações, como, por exemplo, os coluviões referidos por LEPSCH (1977) e descritos como depósitos sedimentares mais recentes da região de Echaporã. AB'SABER (1969b), retomando a classificação das formações cenozoicas de São Paulo, refere-se a MORAES REGO (1933 apud AB'SABER 1969b), que subdivide as camadas quaternárias em antigas e modernas. Nestas últimas talvez possam ser incluídos alguns depósitos tecnogênicos.

MELO \& PONÇANO (1983) não incluem em sua sistematização do conhecimento sobre a gênese, distribuição e estratigrafia dos depósitos cenozoicos no Estado de São Paulo, nenhuma observação sobre depósitos antrópicos.

Tem-se registrado, entretanto, relatos informais que, durante reconhecimentos ou levantamentos de campo, alguns depósitos tenham sido equivocadamente reconhecidos, pelo menos num primeiro momento, como sedimentos terciários ou cenozoicos. Ou então, que, tendo sido constatada, não sem certa surpresa, a presença de restos de artefatos, ou objetos manufaturados, em suas camadas, denunciando forte componente artificial na sua origem, tenham sido excluídos dos levantamentos voltados especificamente à caracterização de formações geológicas ou coberturas pedológicas naturais. 
No Planalto Ocidental Paulista, vários fundos dos vales apresentam estes indicadores e os relatos de antigos moradores atestam o processo catastrófico de colmatação dos fundos vales, nas primeiras décadas do século XX (Figura 3).
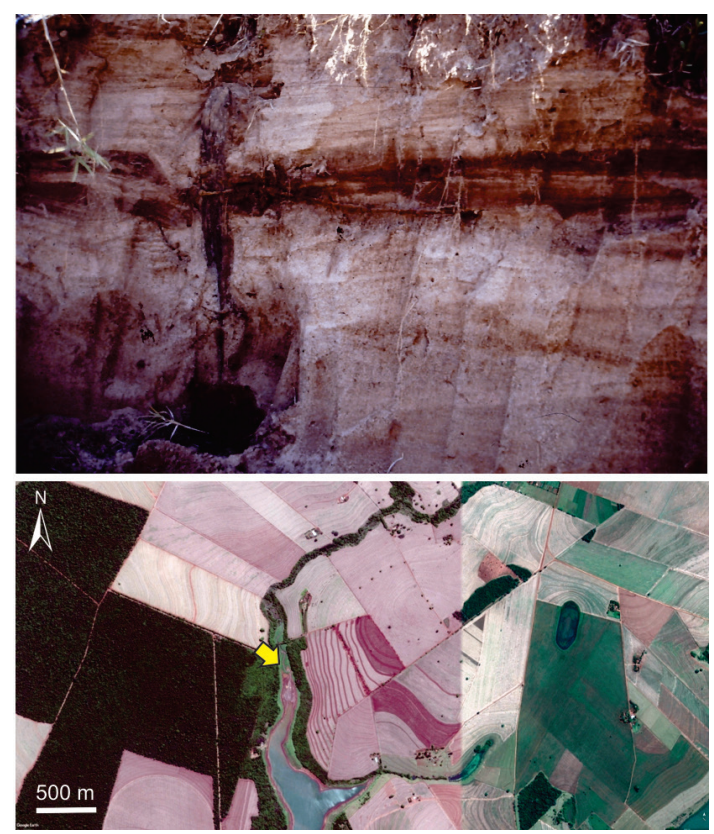

Figura 3 - Morão de cerca e arame farpado enterrados em depósito tecnogênico em Iepê (1990). Abaixo, imagem de satélite Digital Globe (Fonte: Google Earth) da área (Córrego do Iepê, Bacia do Rio Paranapanema, Município de Iepê).

O fato é que não há, até o momento, mapeamentos sistemáticos destes depósitos que, no entanto, têm larga distribuição no Planalto Ocidental, como atestam as observações efetuadas nos trabalhos de campo do Projeto "Orientações para o combate à erosão no Estado de São Paulo" (DAEE 1989).

A pesquisa de fotos aéreas antigas (Figura 4), os relatos de moradores e a análise das camadas que compõem os depósitos tecnogênicos dos fundos dos vales indicam escoamentos de alta intensidade, com a presença de artefatos pesados como frascos e tijolos, e, em alguns locais, estratificação cruzada. Entretanto, a estratificação mais frequente é a planoparalela com a intercalação de estratos arenosos de areias médias e grossas (estratos claros e mais espessos) e areias finas com mais argila (mais escuros e menos espessos), indicando a intermitência dos escoamentos que dependem das chuvas intensas ocasionais.

Segundo DAEE (1989), foram realizados cerca de 300 cadastros de ravinas de grande porte e de

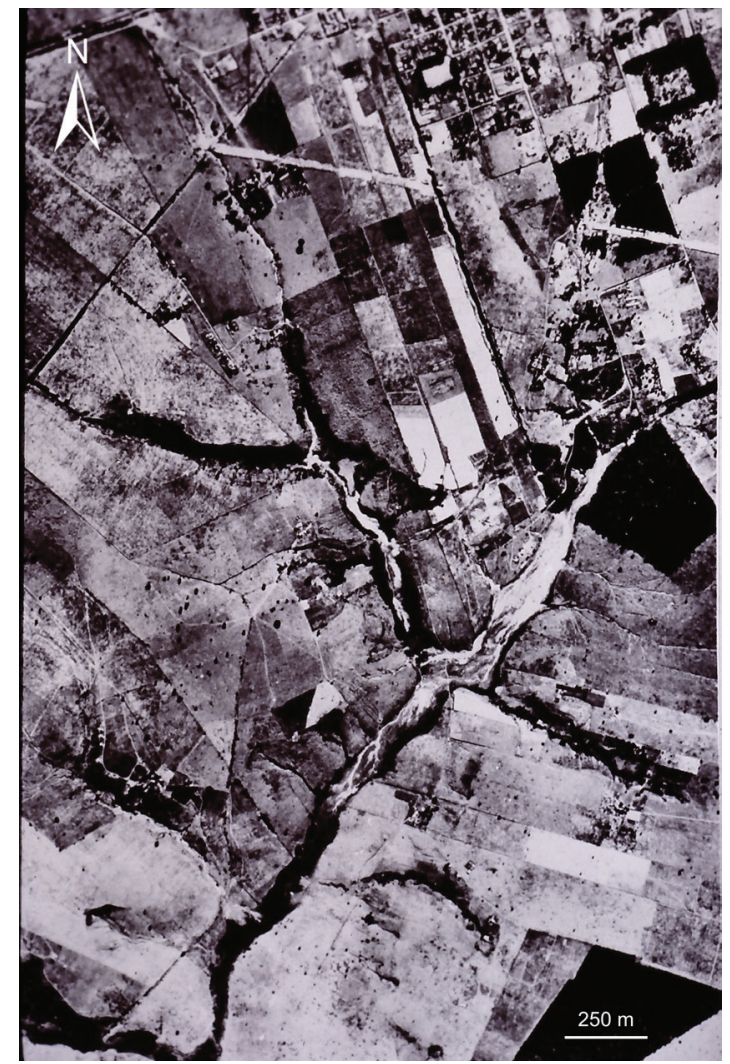

FIGURA 4 - Em foto aérea de Rancharia, de 1962, é possível observar faixas e linhas brancas dos depósitos em processo de formação nos fundos dos vales.

voçorocas nas áreas urbanas e quase 1.000 cadastros na área rural da Bacia do Peixe-Paranapanema, a partir da elaboração de croquis das ocorrências, em escalas da ordem de 1:1.000 (OLIVEIRA 1990). Foi durante a elaboração dos croquis que os depósitos tecnogênicos passaram a ser reconhecidos. Os primeiros relatos foram divulgados nos anos de 1990 (OLIVEIRA 1990, OLIVEIRA \& QUEIROZ NETO 1994). Para todo o Planalto Ocidental podese estimar a existência de milhares de voçorocas e ravinas de grande porte, com depósitos tecnogênicos correlatos nos fundos dos vales a jusante.

Com base nesses reconhecimentos e cadastros foi possível elaborar, conforme a figura 5 , a forma mais comum de ocorrência de um depósito, quando se encontra exposto pelo entalhamento de um canal fluvial. Nesse modo de ocorrência, sua presença se evidencia pelo contraste dos depósitos avermelhados com os solos hidromórficos brancos, sotopostos, da antiga várzea colmatada (Figura 6). Esse contato dos depósitos é, em geral, plano e bem marcado pelo contraste flagrante de cores: os depósitos possuem cores claras, vermelhas e amarelas, enquanto os solos hidromórficos têm cor cinza, mais ou 


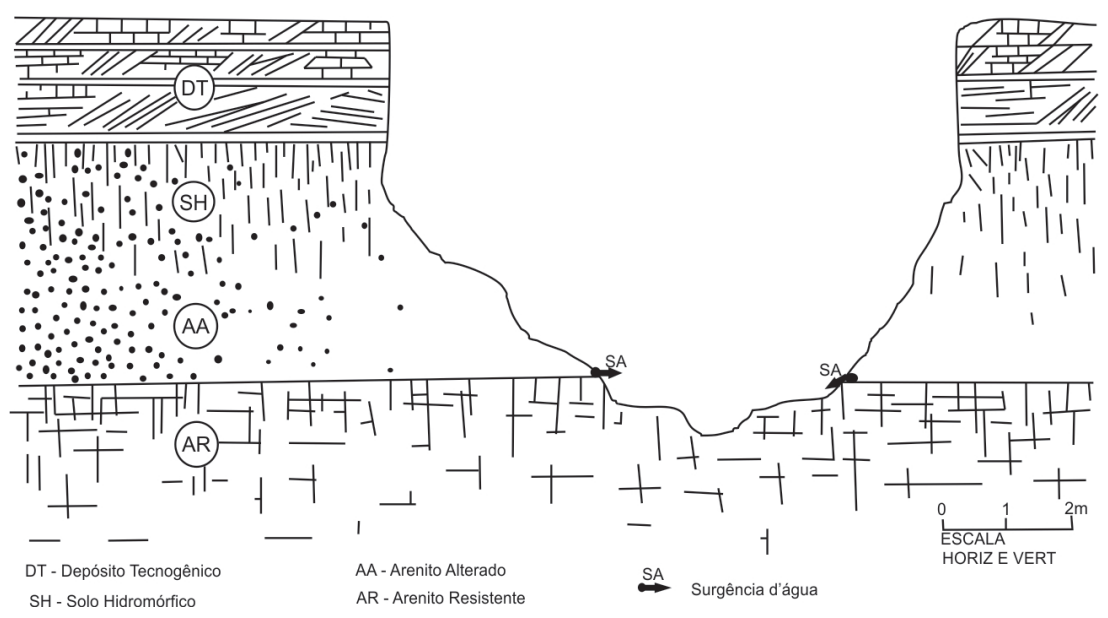

FIGURA 5 - Perfil tipo de um curso d'água entalhado mostrando o depósito e seu embasamento.

menos escuro, dependendo do teor de matéria orgânica presente. Por outro lado, os depósitos são predominantemente arenosos e com estratificação plano-paralela, conferida pela intercalação de camadas arenosas de 10 a $100 \mathrm{~cm}$ de espessura e camadas argilosas de 1 a $10 \mathrm{~cm}$. Estas têm cores mais brunas que as arenosas. As camadas arenosas apresentam, frequentemente, estratificação cruzada, e é nelas que podem ser encontrados restos de artefatos (pedaços centimétricos de tijolos, de telhas,
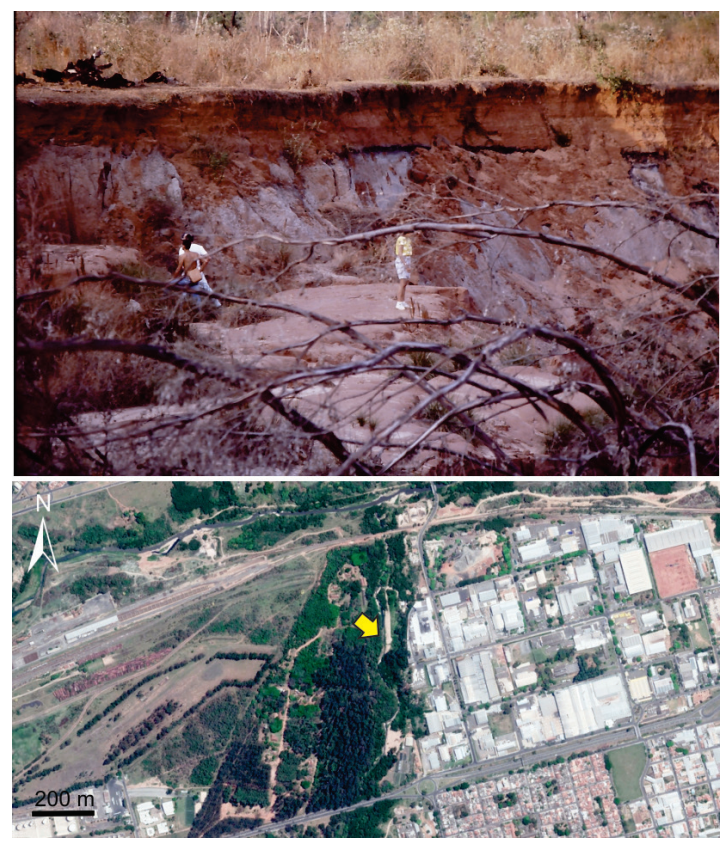

FIGURA 6 - Depósito tecnogênico vermelho sobre solo hidromórfico branco em Bauru (Horto, 1990). Abaixo, imagem de satélite Digital Globe (Fonte: Google Earth) da área (Rio Bauru, Bacia do Rio Tietê, Município de Bauru). de vidros, plásticos, etc.), especialmente quando se trata de depósitos associados à ocupação urbana. $\mathrm{Na}$ base dos depósitos podem ser encontrados pedaços de carvão e restos de madeira, parcial ou totalmente carbonizados, como prováveis testemunhos das primeiras queimadas (Figura 7).

Sua espessura mais frequente é da ordem de 1 a $3 \mathrm{~m}$, tendo-se, entretanto, identificado depósitos com até $8 \mathrm{~m}$ (Figura 8). Ocupam os vales assoreando as planícies de inundação ou formando
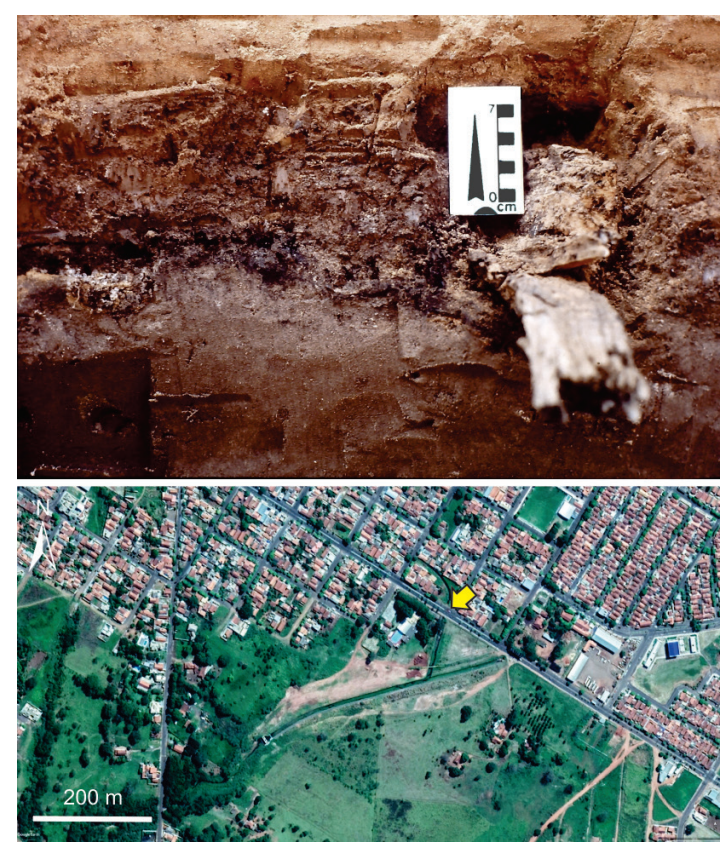

FIGURA 7 - Contato de depósito tecnogênico com solo hidromórfico sotoposto, marcado por carvão e madeira, em Andradina (1989). Abaixo, imagem de satélite Digital Globe (Fonte: Google Earth) da área (Córrego Pereira Jordão, afluente do Rio Moinho, Bacia do Rio Paraná). 


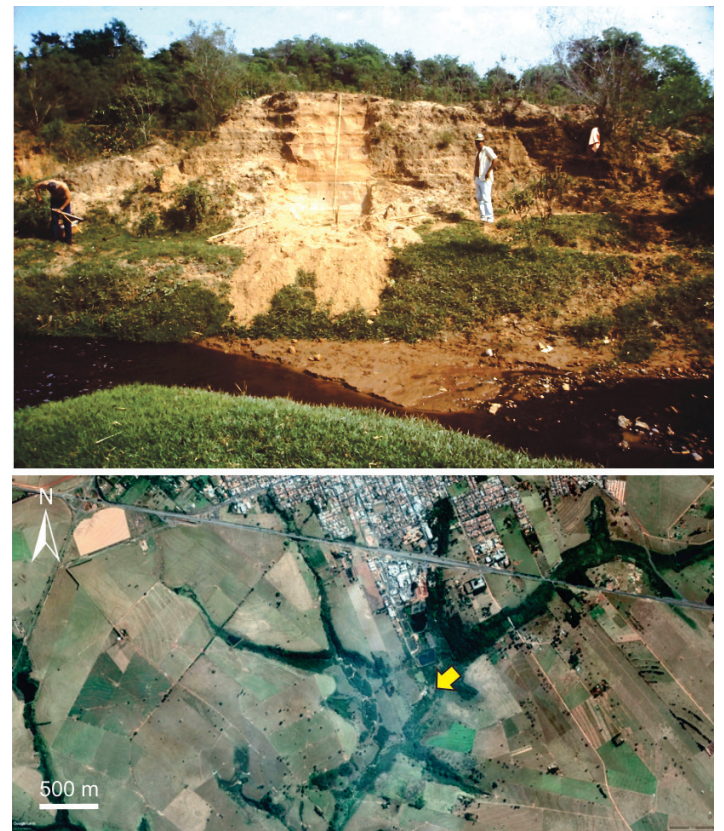

Figura 8 - Depósito tecnogênico de fundo de vale em Rancharia, com $8 \mathrm{~m}$ de espessura (1991). Contato da base com solo hidromórfico identificado por trado. Abaixo, imagem de satélite Digital Globe (Fonte: Google Earth) da área (Ribeirão Rancharia, afluente do Rio Capivari, Bacia do Rio Paranapanema, Município de Rancharia). terraços aluvionares, com larguras de 50 a $200 \mathrm{~m}$, podendo assim se estender por centenas e mesmo por milhares de metros ao longo das drenagens de primeira e segunda ordem. Vales com fundos chatos no Planalto Ocidental Paulista são indicadores da presença de depósitos tecnogênicos que cobrem as várzeas antigas, denunciadas pelos solos hidromórficos sotopostos, pelas raízes de taboas soterradas, e descritas pelos moradores locais que tenham vivenciado as transformações ocorridas. Em geral, os depósitos podem ser correlacionados a fontes importantes de sedimentos, representadas por feições erosivas lineares de grande porte, ravinas ou voçorocas, a montante das ocorrências. Esta correlação entre depósitos e fontes de sedimentos aponta para fenômenos descontínuos de rápida progressão por ocasião de chuvas intensas sobre solos recém expostos pelo desmatamento.

A tabela 1 apresenta as principais características dos depósitos tecnogênicos que ocorrem nos fundos dos vales do Planalto Ocidental Paulista, cujos exemplos aqui ilustrados nas figuras anteriores encontram-se localizados no mapa da figura $1 \mathrm{~B}$ sobre a área de ocorrência da Bacia Bauru.

TABELA 1 - Principais características dos depósitos tecnogênicos que ocorrem nos fundos dos vales do Planalto Ocidental Paulista (OLIVEIRA 1994).

\begin{tabular}{|c|c|c|}
\hline \multicolumn{2}{|c|}{ CARACTERÍSTICAS } & DESCRIÇÃO \\
\hline \multirow{6}{*}{$\begin{array}{l}0 \\
0 \\
0 \\
0 \\
0 \\
0 \\
0 \\
0 \\
0 \\
0 \\
0 \\
0 \\
0 \\
0 \\
0 \\
0 \\
0 \\
0\end{array}$} & $\begin{array}{l}\text { Feições } \\
\text { morfológicas }\end{array}$ & $\begin{array}{l}\text { Planície de inundação, com lâmina d'água rasa, formada por filetes anastomosados e sem canal definido. } \\
\text { Terraço aluvionar com curso d'água em canal entalhado, com paredes abruptas, submetido a erosão fluvial. }\end{array}$ \\
\hline & $\begin{array}{l}\text { Cobertura } \\
\text { vegetal }\end{array}$ & $\begin{array}{l}\text { Solo nu ou coberto por taboas ou gramíneas com arbustos esparsos. } \\
\text { Mata ciliar morrendo ou ausente. }\end{array}$ \\
\hline & $\begin{array}{l}\text { Feições de erosão } \\
\text { correlatas }\end{array}$ & $\begin{array}{l}\text { Voçorocas. } \\
\text { Ravinas. }\end{array}$ \\
\hline & Em fotos aéreas & $\begin{array}{l}\text { Faixas e linhas brancas alongadas, sinuosas e em leque, representando deposições recentes de sedimentos, } \\
\text { sem cobertura vegetal. }\end{array}$ \\
\hline & $\begin{array}{l}\text { Na análise } \\
\text { dinâmica }\end{array}$ & $\begin{array}{l}\text { Desaparecimento progressivo da mata ciliar. Aumento lateral do depósito e progressão para jusante. } \\
\text { Definição e entalhamento progressivo do canal do curso d'água. }\end{array}$ \\
\hline & $\begin{array}{l}\text { Em relatos de } \\
\text { moradores }\end{array}$ & $\begin{array}{l}\text { Soterramento de pontes, monjolo, cercas. Entupimento ou colmatação de canais e poços de pesca. } \\
\text { Assoreamento de açudes. }\end{array}$ \\
\hline \multirow{7}{*}{ 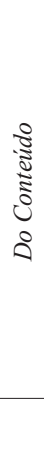 } & Cor & Sedimentos de cores mais claras que as dos solos das áreas-fonte. \\
\hline & Textura & Sedimentos predominantemente arenosos. \\
\hline & Estratificação & $\begin{array}{l}\text { Plano-paralela: camadas arenosas decimétricas de cores vermelhas e amarelas e camadas areno-argilosas } \\
\text { centimétricas de cores brunas. Estratificação cruzada nas camadas arenosas. }\end{array}$ \\
\hline & $\begin{array}{l}\text { Comportamento } \\
\text { mecânico }\end{array}$ & $\begin{array}{l}\text { Sedimentos pouco coesos. Camadas arenosas friáveis. Baixa resistência à penetração do trado. Liquefação } \\
\text { das areias nos furos à trado, sob o lençol freático. }\end{array}$ \\
\hline & Artefatos e obras & $\begin{array}{l}\text { Presença eventual de restos de tijolos, telhas, madeiras, vidro, etc. } \\
\text { Possíveis cercas, monjolos, pontes, etc. }\end{array}$ \\
\hline & Da base do depósito & $\begin{array}{l}\text { Matéria orgânica abundante. Restos vegetais. } \\
\text { Carvão e madeira carbonizada. }\end{array}$ \\
\hline & Do substrato & $\begin{array}{l}\text { Contato brusco com o depósito. Solo hidromórfico ou substrato rochoso. } \\
\text { Resistência à penetração do trado. }\end{array}$ \\
\hline
\end{tabular}




\section{PROPOSTA DA ALOFORMAÇÃO ANDRADINA}

De conformidade com os conceitos expostos e discutidos no item 2.3, a aplicação do conceito de Aloformação é adequada à nomenclatura estratigráfica dos depósitos dos fundos dos vales do Planalto Ocidental Paulista, pois registram e expressam o efeito regional de um evento histórico expressivo no oeste do estado de São Paulo. Como a estratigrafia do Antropoceno ainda não está definida, pois falta-lhe como embasamento a própria definição desta época (ZALASIEWICZ et al. 2011), a Aloformação Andradina, traz implícita a sua origem antrópica mesmo que o período ou época ainda não tenha sido formalmente definido.

Tomado como exemplo, o depósito tecnogênico de Andradina foi estudado em setembro de 1989 (Figura 9). A análise da forma de ocorrência e das características do conteúdo do depósito permitiu a elaboração de hipóteses quanto à sua formação (OLIVEIRA 1990). Os sedimentos foram produzidos por uma voçoroca, cujas cabeceiras chegaram a atingir quarteirões próximos à estação ferroviária e se depositaram sobre o fundo do vale do córrego Pereira Jordão, na periferia da cidade, região sul.

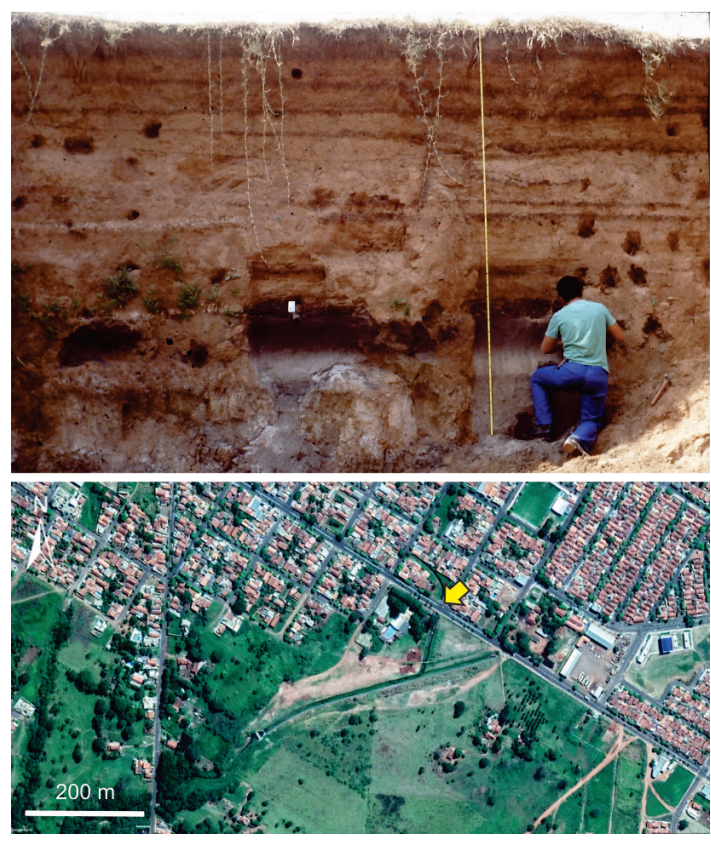

Figura 9 - Vista do depósito tecnogênico de Andradina estudado em 1989. Abaixo, imagem de satélite Digital Globe (Fonte: Google Earth) da área (Córrego Pereira Jordão, afluente do Rio Moinho, Bacia do Rio Paraná, Município de Andradina).
As intercalações de camadas arenosas e argilosas, plano-paralelas, bem como a existência de estratificação cruzada em algumas das camadas arenosas, indicam fases de deposição de sedimentos, transportados por escoamentos superficiais concentrados, de elevada capacidade de transporte, intercaladas a fases sem deposição. O porte das camadas arenosas deve indicar uma combinação de vários fatores, entre os quais se destacam: a disponibilidade de sedimentos na áreafonte e a ocorrência de chuvas intensas, capazes de produzir escoamentos de elevada capacidade de transporte.

O fornecimento de sedimentos, correspondente à atividade dessa voçoroca e aos processos erosivos instalados na área urbana, em processo de implantação, foi o fator que evoluiu com o tempo.

Devido ao controle da voçoroca e à recuperação da área degradada pelo progressivo processo de urbanização, com a pavimentação e o sistema de drenagem das ruas, as áreas fontes foram desativadas e os sedimentos deixaram de ser produzidos nas quantidades em que formavam o depósito. Nesta fase, o escoamento superficial ganhou potencial erosivo, não só porque sofreu redução de sua carga de sedimentos, mas também pelo incremento das vazões, proporcionado pela urbanização.

Interrompeu-se assim a fase de deposição e iniciou-se a de entalhe do canal fluvial que, retrabalhando os depósitos, transportou os sedimentos mais para jusante.

Tendo passado por esse processo, o depósito tecnogênico do Córrego Pereira Jordão, ainda é atualmente acessível em Andradina pela Avenida Rio Grande do Sul, que separa a zona urbana da rural, em frente à rua Benjamin Constant que termina nessa avenida. Como o local permanece em área ainda não urbanizada, o afloramento pode ser acessado.

A denominação Andradina além de representar a localidade que teve o primeiro depósito estudado (OLIVEIRA 1990), constitui um dos principais locais de referência das pesquisas pioneiras realizadas por Pierre Monbeig, nos anos de 1940, e onde é possível reconhecê-la como um estratótipo, não resultante de um evento fortuito ou localizado, mas sim a expressão do quadro geológico configurado pela ação do homem como agente geológico no Planalto Ocidental Paulista. 


\section{CONSIDERAÇÕES FINAIS}

A história ambiental recente do Planalto Ocidental do estado de São Paulo pode ser fundamentada a partir do conhecimento do ambiente quaternário, mais ou menos modificado pelos povos indígenas e pela história de ocupação e uso do solo desde o início do século XX. A alteração do balanço hídrico constitui o eixo principal da análise dessas transformações.

Os fatores de transformação do Planalto, os naturais e os antrópicos, se cruzaram na história geotecnogênica, produzindo resultados jamais reconhecidos no mundo natural. Esta fase erosiva, considerada uma crise morfológica (AB'SABER 1965), uma fase de resistasia antrópica (AB' SABER 1968), comparada a uma mudança climática (QUEIROZ NETO 1978), pode ser caracterizada como um epiciclo erosivo. Ou seja, nas condições naturais do Quaternário, sem alterações significativas do clima, a cobertura vegetal, que deveria continuar a existir, desapareceu, alterando o equilíbrio do balanço hídrico.

Desse cenário e como resultado dos processos erosivos tecnogênicos, resultou a Aloformação Andradina, encontrada nos fundos dos vales, de primeira e segunda ordens, colmatados e planos, como planícies aluviais, ou nos fundos entalhados como terraços fluviais, e caracterizada por sedimentos, pouco coesos e estratificados, com a presença ou não de artefatos. Sua expressão em área, identificada na paisagem e pela análise de fotos aéreas, consubstanciada pelos relatos de moradores locais que testemunharam a sua formação, leva a crer que a mesma alcance a condição de estratótipo e camada superficial de origem antrópica, que testemunha a mudança dos processos geológicos (naturais) para os geotecnogênicos (naturais e antrópicos) no Planalto Ocidental Paulista.

Tendo em vista que, aos poucos, o balanço hídrico vai retomando o equilíbrio nas novas condições, os processos erosivos vão se atenuando, e a nova morfogênese vai também adquirindo novo equilíbrio. Este cenário, no entanto, pode ser interrompido em locais específicos, pois as mudanças do uso o solo e do seu manejo sempre vem acompanhadas de alterações hidrológicas, como se comenta a seguir.

Nas áreas rurais destaca-se, como mudança do manejo do solo, a introdução do trator, por volta do final dos anos de 1960, que resultou na criação de horizontes antrópicos, correspondentes a uma camada compactada, conhecida por pé de grade
(KERTZMAN 1996) sotoposta a camada superficial sem coesão e que nas primeiras enxurradas é erodida, expondo, segundo expressão local, as costelas da terra da camada compacta (BRANNSTROM \& OLIVEIRA 2000). As mudanças do uso do solo prosseguem com o avanço da cultura da cana de açúcar sobre áreas de pastagem, a implantação de rede de estradas de diversos portes, a construção de linhas de transmissão, dutos etc. Por outro lado foram introduzidas práticas conservacionistas como o manejo do solo agrícola com sistema conservacionista, como as curvas de nível, o Programa de Microbacias Rurais da Secretaria da Agricultura estadual, iniciado na década de 1990, pela Coordenadoria de Assistência Técnica Integral (CATI) da Secretaria de Estado da Agricultura e do Abastecimento (HESPANHOL 2007) e a gestão de bacias hidrográficas por meio dos Comitês de Bacias do Plano Estadual de Recursos Hídricos do Estado de São Paulo, criados pela Politica Nacional de Recursos Hídricos, instituída na mesma década.

Nas áreas urbanas, a rápida expansão das cidades, a partir da década de 1960 , provocou a reativação, nas periferias, de processos erosivos que estavam apenas iniciados como resposta aos desmatamentos. Assim, a erosão linear, cuja intensidade ia aos poucos sendo atenuada na zona rural, "deslocou-se" para as zonas urbanas, acompanhando o êxodo rural e a migração para as cidades (OLIVEIRA 1994). Nesse contexto as expansões das periferias urbanas promoveram um maior escoamento superficial, concentrado pela malha viária para os vales como o notável exemplo de Monte Alto (ALMEIDA FILHO et al. 2009).

A partir da década de 1960, destaca-se, ainda, o ciclo dos barramentos sucessivos dos principais rios da região: Tietê (SP), Paranapanema (SP/PR), Paraná (SP/MS) e Grande (SP/MG), podendose dizer que a região de caráter fluvial, tornouse uma região lacustre, com o represamento de águas em reservatórios com um volume total da ordem de mais de 100 bilhões de metros cúbicos e uma somatória dos perímetros de quase duas vezes o comprimento do litoral brasileiro. Resulta destes empreendimentos, além de outros impactos ambientais, a ascensão dos níveis freáticos com produção de processos erosivos marginais, ao longo dos fundos dos vales, devido à saturação dos terrenos.

Entretanto, em escala regional, podese reconhecer a superioridade da intensidade da primeira intervenção sobre as seguintes, pelo simples fato de que, em poucos anos, foi 
praticamente suprimido o componente biótico natural do meio ambiente geológico que vinha evoluindo de forma contínua ao longo do Quaternário e, num momento geologicamente instantâneo, catastrófico, foi introduzido o agente antrópico, sobretudo no período em que houve a presença dos colonizadores europeus.

Verifica-se atualmente, no século XXI, que os processos erosivos no Planalto Ocidental Paulista, especialmente as boçorocas, vão perdendo intensidade atingindo aos poucos certo equilíbrio, de tal forma que as idades das boçorocas ainda existentes nessa região correspondem ao tempo de ocupação dos terrenos (PONÇANO \& PRANDINI 1987). A redução do aporte de sedimentos favorece o entalhe dos depósitos tecnogênicos formados nos fundos dos vales. Com estas alterações históricas os depósitos tecnogênicos vão sendo entalhados e erodidos, havendo cursos d'água em que não é mais possível encontrar uma ocorrência, embora possam ser delimitados numa foto aérea antiga.

Complementam os agentes de transformação do meio ambiente do Planalto as mudanças climáticas que, como os processos geotecnogênicos da dinâmica superficial, mesclam forçantes naturais e antrópicas, conforme os relatórios do International Panel on Climate Change (IPCC), indicando que as transformações antrópicas do meio ambiente, iniciadas localmente, nas aldeias indígenas, foram além da expressão regional, no período da colonização europeia, e atingiram a dimensão global. Todas as dimensões agora se entrelaçam em complexas relações de causas e efeitos, gerando processos dinâmicos atuais de transformação do meio ambiente, cujas paisagens resultantes só a história geoambiental pode elucidar, a partir de pesquisas de registros e indicadores, sejam naturais ou antrópicos, entre os quais se destacam os depósitos tecnogênicos. A Aloformação Andradina é um exemplo, que testemunha a colonização europeia, como um marco do Antropoceno no Planalto Ocidental Paulista.

\section{AGRADECIMENTOS}

Os autores são gratos ao colega Prof. Dr. Fernando Nadal Junqueira Villela, do Departamento de Geografia da Faculdade de Filosofia, Letras e Ciência Humanas da Universidade de São Paulo, pela cuidadosa revisão do artigo; aos editores da Revista do IG, em especial Dr. Silvio Takashi Hiruma, e Dr. Alex Ubiratan Goosens Peloggia pelo prestimoso apoio, assim como aos relatores que contribuíram com atenciosas revisões.

\section{REFERÊNCIAS BIBLIOGRÁFICAS}

AB'SABER, A.N. 1965. Da participação das depressões periféricas e superficies aplainadas na compartimentação do planalto brasileiro. Instituto de Geografia, Universidade de São Paulo, São Paulo, Tese de Livre Docência, $178 \mathrm{p}$.

AB'SABER, A.N. 1968. As boçorocas de Franca. Revista da Faculdade de Filosofia, Ciências e Letras de Franca, 1(2): 5-27.

AB'SABER, A.N. 1969a. Um conceito de Geomorfologia a serviço das pesquisas sobre o Quaternário. Geomorfologia, 18: 1-23.

AB'SABER, A.N. 1969b. Uma revisão do quaternário paulista: do presente para o passado. Revista Brasileira de Geografia, 31(4): 1-51.

ALMEIDA, F.F.M. 1964. Os fundamentos geológicos do relevo paulista. Boletim do Instituto Geográfico e Geológico, 41: 169-263.

ALMEIDA, F.F.M.; HASUI, Y.; PONÇANO, W.L.; DANTAS, A.S.L.; CARNEIRO, C.D.R.; MELO, M.S.; BISTRICHI, C.A. 1981. Mapa geológico do estado de São Paulo. Nota Explicativa. São Paulo: IPT, 2 v. (Monografias, 6).

ALMEIDA FILHO, G.S.; GOMES, C.L.R.; HELLMEISTER Jr., Z. 2009. Processo de instabilização em cabeceira de drenagem na área urbana do município de Monte Alto, SP. In: ABGE, SIMPÓSIO NACIONAL DE CONTROLE DE EROSÃO, 8, São Paulo, http:// www.acquacon.com.br/8snce/modelo.pdf

ALONSO, M.T.A. 1977. Vegetação. In: Fundação Instituto Brasileiro de Geografia e Estatística, Geografia do Brasil: Região Sudeste. Rio de Janeiro, IBGE. v.3, p. 91-118.

BITTENCOURT, A.V.L. 1978. Sólidos hidrotransportados na bacia hidrográfica do Rio Ivai: aplicação de balanços hidrogeoquimicos na compreensão dos processos da dinâmica externa. Instituto de Geociências, Universidade de São Paulo, São Paulo, Tese de Doutorado, 
201 p. http://dx.doi.org/10.11606/t.44.1978. tde-15072015-160924

BRANNSTROM, C. 1998. After the Forest: Environment, Labor, and Agro-Commodity Production in Southeastern Brazil. University of Wisconsin-Madison, Madison, PhD Thesis, 3 v., 771 p.

BRANNSTROM, C. 2002. Rethinking the "Atlantic Forest" of Brazil: New Evidence for Land Cover and Land Value in Western São Paulo, 1900-1930. Journal of Historical Geography, 28(3): 420-39. https://doi. org/10.1006/jhge.2002.0459

BRANNSTROM, C.; OLIVEIRA A.M.S. 2000. Human modification of stream valleys in the Western Plateau of São Paulo, Brazil: implications for environmental narratives and management. Land Degradation \& Development, 11: 535-548. https://doi.org/10.1002/1099$145 \mathrm{X}(200011 / 12) 11: 6 \% 3 \mathrm{C} 535::$ AID LDR412\%3E3.0.CO;2-L

CASTRO, S.S. 1989. Sistemas de transformação pedológica em Marília, SP: B Latossólicos e $B$ texturais. Faculdade de Filosofia, Letras e Ciências Humanas, Universidade de São Paulo, São Paulo, Tese de Doutorado, 274 p.

CHEMEKOV, Y.F. 1983. Technogenic deposits. In: INQUA, INTERNATIONAL QUATERNARY CONGRESS, 11, Moscow, Abstracts, v. 3, p. 62.

CRUTZEN, P.J.; STOERMER, E.F. 2000. The Anthropocene. Global Change News Letter, 41: 17-18.

DAEE - DEPARTAMENTO DE ÁGUAS E ENERGIA ELÉTRICA. 1989. Controle de erosão; bases conceituais e técnicas. Diretrizes para o planejamento urbano $e$ regional. Orientações para o controle de boçorocas urbanas. DAEE/IPT, São Paulo, $92 \mathrm{p}$.

DEAN, W. 2004. A ferro e fogo: a história e a devastação da Mata Atlântica brasileira. Cia. das Letras, São Paulo, $1^{a}$ ed., 484 p.

ERHART, H. 1956. La génese des sols em tant que phenomène géologique: esquisse d'une théorie géologique et géoquimique. Biostasie et Rhesistasie, Masson, $90 \mathrm{p}$.
ETCHEBEHERE, M.L. 2002. Aloestratigrafia revisão de conceitos e exemplos de aplicação, com ênfase nos depósitos neoquaternários de terraço da bacia do rio do Peixe, SP. Geociências, 7(6): 15-34.

ETCHEBEHERE, M.L.; SAAD, A.R.; FÚLFARO, V.J. 1999. Neotectônica no Vale do Rio do Peixe, SP - Evidências de deformação em sedimentos neocenozóicos. In: SBG, SIMPÓSIO DE GEOLOGIA DO SUDESTE, 6, São Pedro, Boletim de Resumos, p. 94.

ETCHEBEHERE, M.L.; SAAD, A.R.; CASADO, F.C. 2005. Análise morfoestrutural aplicada no vale do Rio do Peixe (SP): uma contribuição ao estudo da neotectônica e da morfogênese do Planalto Ocidental Paulista. Geociências, X(6): 45-62.

FLORENCE, H. 1977. Viagem fluvial do Tietê ao Amazonas de 1825 a 1829. Tradução de Visconde de Taunay. Cultrix - Edusp, São Paulo, 311 p.

GUIDICINI, G.; SILVA, R.F. 1972. Sobre a ocorrência de uma extensa bacia de acumulação de sedimentos rudáceos na região de Três Lagoas, sudeste de Mato Grosso. In: SBG, CONGRESSO BRASILEIRO DE GEOLOGIA, 26, Belém, vol.1. p. 155-165.

HAPP, S.C.; RITTENHOUSE, G.; DOBSON, G.C. 2008 [1940]. Some principles of accelerated stream and valley sedimentation. US Department of Agriculture Technical Bulletin 695 (Classics in Physical Geography Revisited). Progress in Physical Geography, 32(3): 337-345. https://doi. org/10.1177\%2F0309133308091947

HESPANHOL, A.N. 2007. O desenvolvimento rural na França e no Brasil: as experiências leader no centro oeste da Bretanha e do Programa de Microbacias Hidrográficas no Estado de São Paulo. In: CONGRESSO EUROPEU DE AMERICANISTA CEISAL, Bruxelas, $15 \mathrm{p}$.

IWASA, O.Y.; PRANDINI, F.L. 1980. Diagnóstico da origem e evolução de boçorocas: condição fundamental para a prevenção e correção. In: ABGE, SIMPÓSIO NACIONAL DE CONTROLE DA EROSÃO, 1, Curitiba, 1980. Anais, p. 5-34. 
JOHNSON, W.C.; CANTWELL, H.D.; DEAN, T.A. 1980. The impact of agricultural settlement on Canadian Sandy Creek, Oklahoma. Proceedings of the Oklahma Academy of Sciences, 60: 82-88.

KERTZMANN, F.F. 1996. Modificações na estrutura e no comportamento de um latossolo roxo provocadas pela compactação. 1996. Faculdade de Filosofia, Letras e Ciências Humanas, Universidade de São Paulo, São Paulo, Tese de Doutorado, 153 p.

KERTZMAN, F.F.; OLIVEIRA, A.M.S.; SALOMÃO, F.T.; GOUVEIA, M.I.F. 1995. Mapa de erosão do Estado de São Paulo. Revista do Instituto Geológico, 16(Núm. Especial): 31-36. http://dx.doi. org/10.5935/0100-929X.19950008

LEITÃO FILHO, H.F. 1992. A flora arbórea dos cerrados do estado de São Paulo. Hoehnea, 19: 151

LEITE, J.F. 1970. A Alta Sorocabana e o espaço polarizado de Presidente Prudente. Faculdade de Filosofia, Ciências e Letras, UNESP, Presidente Prudente, Tese de Doutorado, 249 p.

LEOPOLD, L.B.; WOLMAN, M.G.; MILLER, J.P. 1964. Fluvial Processes in Geomorphology. Ed. Freeman, San Francisco, 544 p.

LEPSCH, I.F. 1977. Superfícies geomorfológicas e depósitos superficiais neocenozoicos em Echaporã. Boletim Paulista de Geografia, 53: 5-34

MELLO, C.L. 1997. Sedimentação e tectônica cenozóicas no médio Vale do Rio Doce (MG, sudeste do Brasil) e suas implicações na evolução de um sistema de lagos. Instituto de Geociências, Universidade de São Paulo, São Paulo, Tese de Doutorado, 275 p. http://dx.doi.org/10.11606/T.44.1997.tde22122015-102604

MELO, M. S.; PONÇANO, W. L. 1983. Gênese, Distribuição e Estratigrafia dos Depósitos Cenozóicos no Estado de São Paulo. IPT, São Paulo, 74 p.

MELO, M.S.; COIMBRA, A.M.; CUCHIERATO, G. 2001. Genesis of Quaternary colluvial eluvial sedimentar covers in Southeaster Brazil. Quaternaire, 12(3): 179-188.

MONBEIG, P. 1984. Pioneiros e fazendeiros de São Paulo. São Paulo, HUCITEC, Polis, 392 p.

MONTEIRO, C.A.F. 1973. A dinâmica climática e as chuvas no Estado de São Paulo. Instituto de Geografia, Universidade de São Paulo, São Paulo, 130 p.

MONTEIRO, C.A.F. 1976. Clima e organização do espaço no Estado de São Paulo: problemas $e$ perspectivas. Instituto de Geografia, Universidade de São Paulo, São Paulo, 54 p.

MORAES REGO, L.F. 1933. As formações cenozóicas de São Paulo. Annuario da Escola Polytechnica, 2: 231-267.

MOURA, J.R.S.; MELLO, C.L. 1991. Classificação aloestratigráfica do quaternário superior na região de Bananal (SP/RJ). Revista Brasileira de Geociências, 21(3): 236-254. http:// dx.doi.org/10.25249/0375-7536.1991236254

OLIVEIRA, A.M.S. 1990. Depósitos tecnogênicos associados à erosão atual. In: ABGE, CONGRESSO BRASILEIRO DE GEOLOGIA DE ENGENHARIA, 6, Salvador, Anais, v.1, p. 411-418.

OLIVEIRA, A.M.S. 1994. Depósitos tecnogênicos $e$ assoreamento de reservatórios. Exemplo do reservatório de Capivara, rio Paranapanema,SP/PR. Departamento de Geografia, Faculdade de Filosofia, Letras e Ciências Humanas, Universidade de São Paulo, São Paulo, Tese de Doutorado, 211 p.

OLIVEIRA, A.M.S.; BRANNSTROM, C. 2004. Fundamentos da história ambiental do Planalto Ocidental do Estado de São Paulo. In: ENCONTRO ESTADUAL DE HISTÓRIA DA ANPHU-BA, 2, Feira de Santana, Anais Eletrônicos.

OLIVEIRA, A.M.S.; PELOGGIA, A.U.G. 2014. The Anthropocene and the Technogene: stratigraphic temporal implications of the geological action of humankind. Quaternary and Environmental Geosciences, 5(2): 103-111. http://dx.doi.org/10.5380/abequa. v5i2.34828 
OLIVEIRA, A.M.S.; QUEIROZ NETO, J.P. 1994 Depósitos tecnogênicos induzidos pela erosão acelerada no Planalto Ocidental Paulista. Boletim Paulista de Geografia, 73: 91-123.

OLIVEIRA, A.M.S.; BRANNSTROM, C.; NOLASCO, M.C.; PELOGGIA, A.U.G.; PEIXOTO, M.N.O.; COLTRINARI, L. 2005. Tecnógeno: registros da ação geológica do Homem. In: C.R.G. Souza, K. Suguio, A.M.S. Oliveira, P.E. Oliveira (eds.) Quaternário do Brasil. Ribeirão Preto, Holos, p. 363-378.

PELLERIN, J.; QUEIROZ NETO, J.P.; HERZ, R. 1975. Formations superficielles et érosion des sols dans la région de Marilia lors des pluies exceptionnelles de 2 au 4 octobre 1972. In: SIMPÓSIO QUATERNÁRIO DA ABEQUA, Curitiba.

PELOGGIA, A.U.G. 1998. O Homem e o Ambiente Geológico (Geologia, sociedade e ocupação urbana no Município de São Paulo). São Paulo, Xamã, 271 p.

PELOGGIA, A.U.G. 2003. O problema estratigráfico dos depósitos tecnogênicos. In: ABEQUA, CONGRESSO DA ASSOCIAÇÃO BRASILEIRA DE ESTUDOS DO QUATERNÁRIO, 9, Recife, Anais, CD-ROM. Disponível em http://www. abequa.org.br/trabalhos/projeto_43.pdf

PELOGGIA, A.U.G.; OLIVEIRA, A.M.S.; OLIVEIRA, A.A.; SILVA, E.C.N.; NUNES, J.O.R. 2014. Technogenic geodiversity: a proposal on the classification of artificial ground. Quaternary and Environmental Geosciences, 5(1): 28-40. http://dx.doi. org/10.5380/abequa.v5i1.34823

PENTEADO, M.M.; RANZANI, G.; SILVEIRA J.D. 1973. Concreções ferruginosas, paleossolo e superfícies de cimeira no Planalto Ocidental Paulista. São Paulo: IGEOG/USP, 28 p. (Geomorfologia, 31).

PERROTTA, M.M.; SALVADOR, E.D.; LOPES, R.C.; D'AGOSTINO, L.Z.; PERUFFO, N.; GOMES, S.D.; SACHS, L.L.B.; MEIRA, V.T.; GARCIA, M.G.M.; LACERDA FILHO, J.V. 2005. Mapa Geológico do Estado de São Paulo, escala 1:750.000. São Paulo, CPRM, Programa Geologia do Brasil - PGB.

PICCHIA, M. 1927. São Paulo e o café. São Paulo e a sua evolução. Centro Paulista, Rio de Janeiro, p. 45-56.

PINHEIRO, M.R. 2014. Estudo morfotectônico da região da Serra de São Pedro e do Baixo Piracicaba. SP. Faculdade de Filosofia, Letras e Ciências Humanas, Universidade de São Paulo, Tese de Doutorado, 286 p. http:// dx.doi.org/10.11606/T.8.2014.tde-11052015170604

PINHEIRO, M.R.; QUEIROZ NETO, J.P. 2016. Geomorphology of the São Pedro ridge and Lower Piracicaba River region, Southeastern Brazil. Journal of Maps, 12: 377-386. https:// doi.org/10.1080/17445647.2016.1227730

PONÇANO, W.L.; PRANDINI, F.L. 1987. Boçorocas no Estado de São Paulo: uma revisão. In: ABGE, SIMPÓSIO NACIONAL DE CONTROLE DE EROSÃO, 4, Marília, Atas, São Paulo, p.149-177.

PONÇANO, W.L.; CARNEIRO, C.D.R.; BISTRICHI, C.A.; ALMEIDA, F.M.; PRANDINI, F.L. 1981. Mapa geomorfológico do Estado de São Paulo. IPT, Monografias 5, Publicação IPT 1183, 2 vols.

PRANDINI, F.L.; GUIDICINI, G.; BOTTURA, J.A.; PONCANO, W.L.; SANTOS, A.R. 1976. Atuação da cobertura vegetal na estabilidade de encostas: uma resenha crítica. São Paulo, IPT. 22 p. ( $2^{\circ}$ Congresso Brasileiro de Florestas Tropicais, Mossoró, RN) (Publicação, 1074)

PRANDINI，F.L.; IWASA， O.Y.; OLIVEIRA, A.M.S. 1982. A cobertura vegetal nos processos e evolução do relevo: o papel da floresta. In: IF, CONGRESSO BRASILEIRO DE ESSÊNCIAS NATIVAS, Campos de Jordão, Anais, v. 3, p. 1568-1582.

QUEIROZ NETO, J.P. 1978. Les problèmes de l'érosion accélérée dans l'État de São Paulo, Brésil. Geo-Eco-Trop, 2: 205-220.

QUEIROZ NETO, J.P.; JOURNAUX, A. 1978. Carta de formações superficiais do Vale do Rio do Peixe em Marília, SP. São Paulo, 
IGEOG/USP (Sedimentologia e Pedologia, 11).

QUEIROZ NETO, J.P.; JOURNAUX, A.; PELLERIN, J. 1977. Formações superficiais da região de Marilia, SP. São Paulo, IGEOG/ USP (Sedimentologia e Pedologia, 8).

RAWITSCHER, F. 1944. Problemas de fitoecologia, com considerações especiais sobre o Brasil Meridional. São Paulo, Faculdade de Filosofia de São Paulo. 154 p. (Boletim Botânica, 41).

RIBEIRO, M.C.R.; MOURA, J.R.S.; MELLO, C.L.; SALGADO C.M.S. 1996. Caracterização pedológica de depósitos coluviais tecnogênicos no médio vale do rio Paraíba do Sul - região de Bananal (SP/RJ). In: SBG, CONGRESSO BRASILEIRO DE GEOLOGIA, 39, Salvador, Anais, v.2, p. 493-495.

RICH, J.L. 1953. Problems in brazilian geology and geomorphology suggested by reconnaissance in summer 1951. São Paulo, Faculdade de Filosofia, Ciências e Letras, Universidade de São Paulo, 80 p. (Boletim 146, Geologia 9). https://doi.org/10.11606/issn.2526-3862. bffcluspgeologia.1953.121715

RODRIGUES, J.E. 1982. Estudo de fenômenos erosivos acelerados: boçorocas. Escola de Engenharia São Carlos, Universidade de São Paulo, São Carlos, Tese de Doutorado, 162 p.

ROEHL, J.W.; HOLEMAN, J.N.; JONES, V.H. 1977. Accelerated valley deposits. In: V.A. Vanoni. Sedimentation engineering. New York, ASCE, p. 382-388.

ROSS, J.L.S.; MOROZ, I.C. 1997. Mapa geomorfológico do estado de São Paulo. Laboratório de Geomorfologia, Faculdade de Filosofia, Letras e Ciências Humanas, Universidade de São Paulo, IPT/FAPESP, 63 p.

RUSTOMJI, P.E.; PIETSCH, T. 2007. Alluvial sedimentation rates from southeastern Australia indicate post-European settlement landscape recovery. Geomorphology, 90(1-2): 73-90. https://doi.org/10.1016/j. geomorph.2007.01.009

SALIS, S.M.; SHEPERD, G.J; JOLY, C.A. 1995. Floristic comparison of mesophytic semide- ciduous forests of the interior of the state of São Paulo, southeast Brazil. Vegetatio, 119: 155-164.

SALLUN, A.E.M.; SUGUIO, K. 2006. Depósitos quaternários da região entre Marília e Presidente Prudente (SP). Revista Brasileira de Geociências, 36(3): 385-395. https://doi. org/10.25249/0375-7536.2006363385395

SALLUN, AE.M.; SUGUIO, K.; STEVAUX, J.C. 2007. Proposição Formal do Alogrupo Alto Rio Paraná (SP, PR e MS). Geologia USP Série Cientifica, 7(2): 49-70. https://doi. org/10.5327/Z1519-874x2007000200004

SANTANA, M.A. 1991. Avaliação dos fatores responsáveis pela fragilidade dos solos na região de Marilia, SP. Faculdade de Filosofia, Letras e Ciências Humanas, Universidade de São Paulo, São Paulo, Dissertação de Mestrado.

SQS - SUBCOMMISSION ON QUATERNARY STRATIGRAPHY - WORKING GROUP ON THE ANTHROPOCENE. 2017 What is the 'Anthropocene'? - current definition and status. Disponível em http://quaternary.stratigraphy.org/workinggroups/anthropocene/. Acessado em 25 abr. 2017.

TER-STEPANIAN G. 1988. Beginning of the Technogene. Bulletin of the IAEG, 38: 133142.

TOIVANEN, T.; LUMMAA, K.; MAJAVA, A.; JÄRVENSIVU, P.; LÄHDE, V.; VADEN, T.; ERONEN, J.T. 2017. The many Anthropocenes: A transdisciplinary challenge for the Anthropocene research. The Anthropocene Review, 4(3): 183-198. https:// doi.org/10.1177\%2F2053019617738099

TORRES, R.B.; MARTINS, F.R.; KINOSHITA, L.S. 1997. Climate, soil and tree relationships in forests in the state of São Paulo, southeastern Brazil. Revista Brasileira de Botânica, 20: 41-49. http://dx.doi.org/10.1590/S010084041997000100004

VARGAS, M. 1973. Structurally Unstable Soils of Southern Brazil. In: INTERNATIONAL CONFERENCE ON SOIL MECHANICS AND FOUNDATION ENGINEERING, 8, Moscow, vol 2, p. 239-249. 
VICTOR, M.A. 1974. A cobertura vegetal primitiva. Sociedade Brasileira de Silvicultura, São Paulo, 48 p.

VIEIRA, N.M. 1978. Estudo geomorfológico das voçorocas de Franca - SP. Instituto de História e Serviço Social, Universidade Estadual Paulista, Franca, Tese de Doutorado, 255 p.

VIEIRA, S.R.; LOMBARDI NETO, F.; BURROWS, I.T. 1991. Mapeamento da chuva diária máxima provável para o estado de São Paulo. Revista Brasileira de Ciência do Solo, 15: 93-98.

VORTICE DANCE COMPANY. 2015. Your Majesties. Welcome to the Anthropocene. Teatro Bradesco. 27 e 28 de março de 2015. https://www.teatrobradescorio.com.br/ Programacao/75_vortice+dance+company

WAIBEL, L. 1955. As zonas pioneiras do Brasil. Revista Brasileira de Geografia, 17(4): 389422.

WALLING,D.E. 1983. The sediment delivery problem. Journal of Hydrology, 65(1-3): 209-237. https:// doi.org/10.1016/0022-1694(83)90217-2
WILKINSON, B.H. 2005. Human as geologic agents: a deep time perspective. Geology, 33(3): 161-164. https://doi.org/10.1130/ G21108.1

ZALASIEWICZ, J.; WILLIAM, M.; FORTEY, R.; SMITH, A.; BARRY, T.; COE, A.; BOWNO, P.; RAWSON, P.; GALE, A.; GIBBARD, P.; GREGORY, F.; HOUNSLOW, M.; KERR, A.; PEARSON, P.; KNOX, R.; POWELL, J.; WATERS, C.; MARSHALL, J.; OATES, M.; STONE, P. 2011. Stratigraphy of the Anthropocene. Philosofical Transactions of the Royal Society A, 369(1938): 1036-1055. https://doi.org/10.1098/rsta.2010.0315

ZALASIEWICZ, J.; WATERS, C.N.; SUL, J.A.I.; CORCORAN, P.L.; BARNOSKY, A.D.; CEARRETA A.; EDGEWORTH, M.; GAŁUSZKA A.; JEANDEL,C.; LEINFELDER R.; J.R.; SUMMERHAYES, C.; WILLIAMS, M.; WOLFE,A.P.; YONAM, Y. 2016. The geological cycle of plastics and their use as a stratigraphic indicator of the Anthropocene. Anthropocene, 13: 4-17. https://doi.org/10.1016/j.ancene.2016.01.002

Endereço dos autores:

Antonio Manoel dos Santos Oliveira - Rodovia Oswaldo Cruz, 4700, Condomínio Vilas, Bairro Horto, CEP 11680-000, Ubatuba, SP, Brasil.E-mail: amanoel2030@gmail.com

José Pereira de Queiroz Neto - Departamento de Geografia, Faculdade de Filosofia Letras e Ciências Humanas, Universidade de São Paulo, Av. Prof. Lineu Prestes, 338, Butantã, CEP 05508-900, São Paulo, SP, Brasil.E-mail: jpqneto@hotmail.com

Artigo submetido em 9 de janeiro de 2019, aceito em 16 de abril de 2019. 